\title{
Generation, Analysis, and Applications of High Resolution Electricity Load Profiles in Qatar
}

\author{
Islam Safak Bayram ${ }^{\mathrm{a}, \mathrm{b}, *}$, Faraj Saffouri ${ }^{\mathrm{b}}$, Muammer Koc $^{\mathrm{b}}$ \\ ${ }^{a}$ Qatar Environment and Energy Research Institute, Hamad Bin Khalifa University \\ ${ }^{b}$ College of Science and Engineering, Hamad Bin Khalifa University
}

\begin{abstract}
Qatar is known to be one of the most energy-intensive countries in the world, yet very little is known about its electricity consumption patterns. In this paper, we unfold the electricity sector in Qatar by presenting high-resolution electricity load profiles, analyzing the unique consumption patterns, and with case studies, showing how load profiles can be used in applications such as demand-side management, renewable energy integration, and mathematical modeling. Moreover, using load profiles, we propose a methodology to estimate the cooling demand which represents the largest portion of the domestic demand. The data used in this study is collected from the official website of the Gulf Cooperation Council Interconnection Authority (GCCIA), validated by the available public datasets, and span a 12 month period from February 2016 to January 2017. The present paper contains the first high-resolution dataset in the GCC region and the results will shed light into future research studies.
\end{abstract}

Keywords: electricity load profiles, demand side management, duck curve, estimation of cooling load

\section{Introduction}

Over the last decade, both Qatar's peak electricity demand and annual electricity generation have increased more than twofold. Primary drivers of such an unprecedented growth can be listed as : (1) highly subsidized

\footnotetext{
${ }^{*}$ Corresponding author

Email addresses: ibayram@hbku.edu.qa (Islam Safak Bayram), farsaffouri@hbku.edu.qa (Faraj Saffouri), mkoc@hbku.edu.qa (Muammer Koc)
} 
electricity tariffs which are below the benchmark price, (2) fast-growing population both due to high fertility rates and rising expat population, (3) high disposal income driven by rich hydrocarbons resources, (4) intensive demand for cooling during hot summer seasons, and (5) quest for a higher standard of living. In order to keep up with the rising demand, authorities have been periodically investing in multi-billion dollar capacity expansion for new generation, transmission, and distribution network assets [1]. On the other hand, recent revenue losses in oil and gas imports have created a pressing need to utilize energy reserves and existing assets in a more efficient manner. Energy efficiency measures that promote energy star appliances, e.g., lighting, air-conditioning, etc., have already been implemented while the proportion of district cooling has recently increased and led to additional savings in cooling load $[2,3]$.

Even though energy efficiency programs have boosted energy savings, meeting peak electricity demand is still a major issue. In summer 2017, system utilization has exceeded $90 \%$ and customers have experienced several power outages. Furthermore, the power grid operations in Qatar is facing new challenges and uncertainties in the near future. First, Qatar is taking bold steps to generate a sizable portion of its electricity through renewable photovoltaic (PV) systems; the targets are set as 200 MW by 2020 and 2 GW generation capacity by 2030 [4]. Higher shares of non-dispatchable energy sources, such as PV farms, are likely to have disruptive impacts on the power grids. Electricity is a unique commodity that its bulk storage is not feasible at a reasonable cost, hence, entities running the power grids need to monitor, control, and match the supply with demand at all times. On the other hand, Qatar is surrounded by deserts and surface soiling due to dust deposition create significant fluctuations in PV output. To compensate for PV intermittency, dispatchable generators may need to ramp-up and ramp-down more frequently, and this situation will inherently introduce an additional cost and uncertainty to system operations $[4,5,6]$. Furthermore, for the case of PV rooftops, if the time of the PV generation and consumption do not match, PV power output injected back to the grid can cause voltage deviations and degrade power quality. Therefore, it is critical to assess the readiness of Qatar's power grid in a holistic manner.

As a second challenge, Qatar is aiming to remove the subsidies in the energy sector and plans to employ the time of use or dynamic pricing schemes to recover the cost of electricity provisioning [7]. Considering the fact that Qatar has the highest energy subsidy per capita in the world, this shift is 
likely to change the electricity consumption patterns and change the utilization of power system assets. Such pricing techniques are established based on consumption patterns, duration of peak hours, and the type of loads used during peak hours. Hence, it is necessary to examine the customer responses to the new pricing regimes and assess the potential applications of other demand-side management techniques such as direct load control (DLC). The last challenge is the participation to GCC interconnection markets [3]. Recently established energy markets allow Qatar to exchange power with neighboring countries. Qatar generates all of its electricity from natural gas and can exploit unused capacity to sell power to its neighbors who significantly use petroleum as the main source of fuel for electricity. In energy markets, accurate load forecasting, load switching, and contract evaluation play a decisive role in hourly settlements and protect system stability through ancillary markets. To that end, load profiles are widely used in market operations.

In order to analyze Qatar's electricity sector and address the challenges discussed above it is critical to obtain and analyze high-resolution load profile data which are essential for energy economics, renewable integration, and power systems research. In this paper, we unfold the electricity load profiles of Qatar for twelve months. Moreover, with case studies, we show how the load profiles can be used to address the challenges discussed above. In the final section, we propose a methodology to estimate the cost of cooling load using data provided in this paper. To the best of author's knowledge, this is the first study that presents high-resolution load profiles of a country in the GCC region.

\section{Literature Review}

Electricity load profiles have had a central position in power systems research for many decades due to its role in load forecasting, system planning, rate-design, and energy markets $[8,9]$. Accurate load forecasting has direct economic impacts on power system operations because strategic decisions on purchasing and generating power, load switching, and infrastructure development are closely attached to forecasted power. Moreover, deregulation of electricity markets made load forecasting a must for all players. The cost of under- or over-contracting power purchases and then compensating the difference between actual load and the forecasted load by participating in auxiliary or balancing markets can lead to financial losses. Accurate forecasting of both the magnitudes and geographical locations of loads is essen- 
tial in maintaining profit margins [10]. A wide range of models are used to forecast the demand at different time scales and different accuracies. For instance, short-term load forecasting (STLF) (one hour ${ }^{1}$ to one week) are needed to forecast the load and essential to ensure the reliability of supply. On the other hand, medium-term load forecasting (MTLF) that are from one week up to a year are used for modeling prices and negotiation of contracts with other companies [10]. Hence, both STLF and MTLF are of interest in daily electricity market operations. Long-term load forecasting (LTLF) that are longer than a year are mainly employed for planning and infrastructure development. To that end, demand forecasting is at the core of nearly all decisions made in power system operations.

It is important to note that the primary interest is to forecast hourly total system load, as well as, weekly, monthly, and yearly peak demand. In forecasting methods, mean absolute percentage error (MAPE), defined by MAPE $=\frac{100}{T} \sum_{t=1}^{T}\left|\frac{y_{t}-\hat{y}_{t}}{y_{t}}\right|$, where $y_{t}$ is the real value at time $t$ and $\hat{y}_{t}$ is the forecasted value, is often used as the main performance metric. For STLF, it is important to have high accuracy (with MAPE 1-2\%) as the time window may not be enough to make substantial changes in the generator outputs. However, it is hard to obtain high accuracies for longer time horizons as system parameters (i.e., weather, etc.) can show significant variability over the course of prediction period. In addition, STLF is used to estimate power flows and enable system operators to prevent overloading or reduce equipment failures. The common methods used in short-term load forecasting are [9, 11]: (1) Similar day approach which is based on searching recent historical day profiles with similar characteristics such as weather, population, calendar date, customer group, etc.; (2) Regression methods which use a mathematical representation of the electricity load and external parameters mentioned in (1); (3) Time series approach which is based on examining the internal structure (i.e., trend, seasonal variation, or autocorrelation) of the demand data. Common time series approaches include autoregressive moving average (ARMA), autoregressive integrated moving average (ARIMA), autoregressive moving average with exogenous variables (ARMAX), and autoregressive integrated moving average with exogenous variables (ARIMAX). Details of such models can be found in $[9,8,11,12]$. In addition to statistical methods given

\footnotetext{
${ }^{1}$ Some times time horizon less than a day may be referred as very short-term forecast [11]
} 
in (1), (2), and (3), artificial intelligent based (AI-based) non-parametric models such as (4) neural networks; (5) expert systems; (6) Support vector machines; and (7) Fuzzy logic approaches are widely used. The advantage of AI-based systems is that it can handle complexity and non-linearity and can forecast load by analyzing historic patterns. A detailed overview and mathematical examples are presented in reference [11].

MTLF and LTLF models typically use demographic and economic factors such as gross domestic product, employment levels, and population growth as inputs. Commonly used methods for MTLF and LTLF include econometrics, end-use models, and statistical model-based learning. A detailed overview of such models is presented in [9]. It is noteworthy that the accuracy of forecasting methods not only depends on the numerical efficiency of the methods, but also the quality of the analyzed data (i.e., weather, econometrics, etc.). Several case studies for different forecasting horizons are presented in [10] (see Chapter 3.2).

The relationship between electricity load and the climatic conditions such as temperature, relative humidity, wind speed, clouds, etc. has been thoroughly reported $[13,14,15,16]$. For example the study in [13] employs multiple linear regression models to determine the factors affecting electricity demand in Italy. For summer months, the temperature is the most important parameter, while cloud cover is the primary factor from February to April. For the case of Qatar, it is reported in [17] that there is a linear relationship between the peak demand and the average daily temperature. It is important to note that the literature on the effects of electricity demand and meteorological variables are region-specific and cannot be generalized because weather impact varies with geographical location, building code, types, efficiency, and lifestyles.

For the case of Qatar and GCC region, the literature on electric power systems and consumption patterns is sparse. In our early work [18], we presented an overview of smart grids in Qatar and GCC region. In [2], we performed an empirical study on direct-load control of air conditioners in Qatar and showed that significant demand reductions can be achieved for short amount of time. Similarly, in reference [1], we considered potential demand-side management techniques in Qatar, examined the effect of pricing strategies in the border countries, and presented the output of largest behindthe-meter photovoltaic (PV) system in Qatar with a total capacity of 3.3 MW. Integration of PV systems has been a center of attention in Qatar. In [4], authors analyzed long-term solar potential in Qatar using satellite data, 
while in reference [19] global horizontal irradiance (GHI) measurements, the metric used to show the output of a PV system, were presented using data collected from ground measurement devices. Even though PV generation potential in Qatar is quite significant (annual GHI is $2048 \mathrm{kWh} / \mathrm{m}^{2} /$ year), the annual average clearness index is found to be 0.62 . Recall that clearness index represents the ratio of solar energy that can be produced after sunlight pass through atmospheric components such as clouds and aerosols. Hence, on average $38 \%$ of energy is lost. In addition, PV soiling is a major issue in Qatar. Especially sudden sandstorms and aggregated dust deposition on PV panels can reduce monthly PV output up to $20 \%$ in Qatar in the absence of rains or scheduled cleaning, which could be quite challenging and costly defying the ultimate purpose [5, 20]. Degradation in PV output due to soiling is measured by the cleanness index exchange rate and a detailed investigation of PV performance in Qatari environment is presented in [21].

Energy consumption in buildings represent a significant portion of total end-use and modeling, simulation, and analyses have been the topic of numerous studies [22, 23, 24]. In [23], authors evaluated energy consumption data from 20000 buildings and by using machine learning techniques they predicted energy use intensity for entire New York City (1.1 million buildings). Similarly, in work presented in [25], authors developed statistical models to generate household electricity load profiles from historical dataset collected from various Finnish households. The generated models are, then, used to assess demand-side management potential of residential units and showed that on average $7.2 \%$ of the average daily peak could be reduced. Such "bottom-up" approaches require a baseline building models or a good number of samples to reflect the profile of the city or district to be estimated. In addition, reference [26] presents an overview of methods for load profile generation for the residential sector. On the other hand, generating aggregated load profiles for all sectors including commercial and industrial, is nearly impossible as the approach would require confidential information on equipment types located at commercial and industrial premises. For the case of Qatar, building energy consumption profiles are not available, hence we used a "top-down" approach to estimate the cooling load in entire Qatar using the electricity load profiles presented in the next section [27]. Quantification of cooling load in hot and arid climate zones is a necessary step and a vital input for studies on energy efficiency, demand response, district cooling systems and others to devise policies and programs to manage electricity end-use [18]. A study on space cooling in Europe is conducted in [28]. 
This study contains an estimation of national cooling demand across Europe using district cooling systems. Moreover, reference [29] estimates that the space cooling in EU28 countries is $5 \%$ in residential units and $13 \%$ service sector.

\section{System Infrastructure}

\subsection{Power Grid in Qatar}

In this section, we present a detailed overview of the power grid in Qatar. Until the year 1999, the power grid in Qatar was a vertical entity operated by the former Ministry of Electricity and Water. To encourage private sector investments, in the year 2000, the Government of Qatar allowed independent power and water producers to participate in utility sector activities and several generation companies have been selling electricity to satisfy the demands of the country. Moreover, transmission and distribution (T\&D) networks have been run and maintained by Qatar General Electricity and Water Corporation (Kahramaa) who manages an expanding power network composed of more than 12000 substations, $2700 \mathrm{~km}$ transmission lines and 2000 overhead lines [30]. The rating of the transmission and distribution network is $400 / 220 / 132 / 66 / 11 \mathrm{kV}$ [31].

Over the last decade, the electricity demand in Qatar has been experiencing a $7-8 \%$ per annum increase. The peak electricity demand has exceeded 7.8 GW in summer 2017 which implies a system utilization of 92\%. Therefore, the Government of Qatar has commissioned to increase the generation capacity from $8.5 \mathrm{GW}$ to $13 \mathrm{GW}$ by 2019 . Key indicators of electricity consumption and the power grid are depicted in Tables 1 and 2. As shown in Table 1, increasing population and high gross domestic product has lead to a steady growth in electricity generation. Hence, in parallel, peak electricity demand and annual energy consumption have continuously been increasing (presented in Table 2). Moreover, annual load factors (ALFs) are around 60$65 \%$, which is low compared to the power grids in the United States, Europe, and Japan. This is mainly because the electricity demand in summer is very high and there is an enormous unused capacity in winter. It is noteworthy that ALF is calculated based on the following formula

$$
\operatorname{ALF}(\%)=\frac{\text { Electricity Generation in a Year }}{\text { Peak Demand of the Year } \times \text { Total No. of Hours in a Year }} \times 100
$$


For instance, in 2015 electricity generation and peak demand were $41.5 \mathrm{TWh}$ and $7270 \mathrm{MW}$, respectively. Moreover, the total number of hours in a year is taken as 8760 hours. Then, by plugging these parameters into equation (1), ALF for 2015 can be calculated as $65.2 \%$. Notice that in the next sections, we will also use daily load factors (DLF) in which the formula for ALF given in equation (1) is modified to reflect electricity generation in a day, peak consumption of the day, and the total number of hours in a day. A detailed discussion of daily load factors is presented in the next section. It is also noteworthy that the utilization coefficient factor increases from $65 \%$ in 2009 to $85 \%$ in 2015 , which indicates that costly capacity expansions do not offer long-term solutions to meet the growing electricity demand.

Table 1: Qatar Key Indicators: Part 1

\begin{tabular}{cccccc}
\hline Year & Population & $\begin{array}{c}\text { GDP } \\
\text { (billion USD) }\end{array}$ & $\begin{array}{c}\text { Electricity } \\
\text { Gen. (TWh) }\end{array}$ & $\begin{array}{c}\text { Electricity } \\
\text { Cons. (TWh) }\end{array}$ & $\begin{array}{c}\text { No. of } \\
\text { Meters }\end{array}$ \\
\hline 2009 & $1,638,626$ & 97.8 & 24.1 & 22.2 & 234,658 \\
2010 & $1,715,098$ & 125.12 & 28.1 & 26.3 & 252,893 \\
2011 & $1,732,717$ & 167.77 & 30.7 & 28.3 & 272,745 \\
2012 & $1,832,903$ & 186.83 & 34.8 & 32.3 & 288,903 \\
2013 & $2,003,700$ & 198.7 & 34.6 & 32.2 & 293,604 \\
2014 & $2,216,180$ & 206.2 & 38.7 & 36.1 & 310,107 \\
2015 & $2,437,790$ & 164.6 & 41.5 & 38.3 & 329,310 \\
\hline
\end{tabular}

\subsection{GCC Interconnection Grid}

During the last two decades, the members Gulf Cooperation Council have established the GCC interconnection grid and built the necessary infrastructure to link the power grids of the six countries, namely, the State of Qatar, the Kingdom of Saudi Arabia (KSA), the Sultanate of Oman, the State of Kuwait, the Kingdom of Bahrain, and the United Arab Emirates [18]. The main drivers of the interconnection authority are related to cost reductions through shared spinning reserves, deferred and reduced capacity investments, and a more robust system support during emergency cases which is often the case during hot summer periods. Moreover, the usage of cleaner energy sources -compared to petroleum- such as natural gas and solar can lower carbon emissions significantly. 
Table 2: Qatar Key Indicators: Part 2 [32]

\begin{tabular}{ccccc}
\hline Year & $\begin{array}{c}\text { Peak Demand } \\
(\mathrm{MW})\end{array}$ & $\begin{array}{c}\text { Installed } \\
\text { Capacity (MW) }\end{array}$ & $\begin{array}{c}\text { Annual Load } \\
\text { Factor }(\%)\end{array}$ & $\begin{array}{c}\text { Utilization } \\
\text { Coefficient }(\%)\end{array}$ \\
\hline 2009 & 4525 & 5321 & 60.8 & 85 \\
2010 & 5090 & 7830 & 63.1 & 65 \\
2011 & 5375 & 8789 & 60.3 & 61 \\
2012 & 6255 & 8789 & 59 & 71 \\
2013 & 6000 & 8791 & 66 & 68 \\
2014 & 6740 & 8791 & 66 & 77 \\
2015 & 7270 & 8560 & 65.2 & 85 \\
\hline ‡ Utilization Coefficients & (UC) are calculated based on the formula UC = \\
Peak Demand & Installed Capacity
\end{tabular}

Between 2009 and 2015, the GCCIA grid was used for mutual support instances to aid the operation of individual power grid operations. Note that the number of mutual support instances passed 250 events and outage events were reduced significantly [33]. In 2016, GCCIA network allowed members to exchange and trade energy. The annual energy transfer added up to 1.32 TWh which can be translated into $\$ 55.4$ million savings from electricity generation. Additional components of the economics savings in 2016 were [34]:

1. Installed capacity savings which are achieved by reducing the funds for deploying new power plants. Total savings were $\$ 212$ million.

2. Savings from fuel, operation and maintenance (including auxiliary services like frequency control) of power plants. Total savings were $\$ 212.4$ million.

3. $\$ 38$ million savings from shared spinning reserves.

4. Total savings reached $\$ 403$ million which is $3.4 \%$ higher than 2015 .

The utilization of GCCIA network is expected to grow over the next years in order to boost financial savings.

\subsection{Data Collection}

Access to public datasets on electricity consumption in Qatar and in other GCC countries is nearly impossible as the member states have not established responsible entities, such as independent system operators or regional 
Table 3: Sample Data Set Collected from GCC Interconnection Authority[33].

\begin{tabular}{ccccc}
\hline CountryCode & TimeStamp & DemandValue & Temp_Cent & Flag \\
\hline QAT & $4 / 1 / 160: 00$ & 3200 & 18 & $\mathrm{~m}$ \\
QAT & $4 / 1 / 160: 01$ & 3141 & 18 & $\mathrm{~m}$ \\
QAT & $4 / 1 / 160: 02$ & 3141 & 18 & $\mathrm{~m}$ \\
QAT & $4 / 1 / 160: 03$ & 3121 & 18 & $\mathrm{~m}$ \\
QAT & $4 / 1 / 160: 04$ & 3044 & 18 & $\mathrm{~m}$ \\
QAT & $4 / 1 / 160: 05$ & 3040 & 18 & $\mathrm{~m}$ \\
QAT & $4 / 1 / 160: 06$ & 3034 & 18 & $\mathrm{~m}$ \\
QAT & $4 / 1 / 160: 07$ & 3041 & 18 & $\mathrm{~m}$ \\
QAT & $4 / 1 / 160: 08$ & 3129 & 18 & $\mathrm{~m}$ \\
QAT & $4 / 1 / 160: 09$ & 3158 & 18 & $\mathrm{~m}$ \\
QAT & $4 / 1 / 160: 10$ & 3160 & 18 & $\mathrm{~m}$ \\
\hline
\end{tabular}

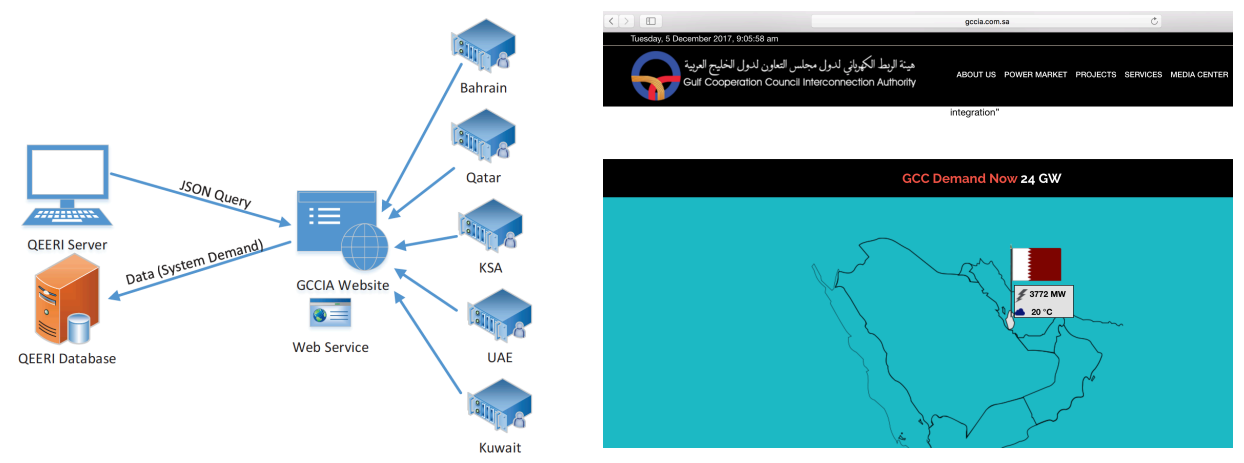

Figure 1: Overview of data collection infrastructure. The figure on the left shows web crawling system and our database and the right figure is a snapshot of the website[33] 
transmission operators in the United States or Europe, to provide such information. This situation, unfortunately, limits research activities on related fields such as demand-side management, energy economics, PV integration, etc. On the other hand, being part of GCCIA network, State of Qatar's and other GCC members' electricity demand are posted in real-time on the official webpage of GCCIA [33]. Hence, to collect the real-time data, we developed a web-crawling program using C-Sharp and created the first electricity demand dataset in the region. In a nutshell, our program visits the GCCIA webpage, searches for keywords, e.g., "qat-mw-val" ${ }^{2}$, related to demand data, retrieves them and stores it in our MySQL database. We created datasets in two different resolutions: five-second and one-minute, which means that at every five seconds and one minute, we establish a connection to GCCIA website. It is noteworthy that the GCCIA website publishes demand data in real-time (ever second) and initially, our program was retrieving data at every second. However, due to security reasons, the website started to decline connection requests as too frequent TCP/IP requests can be recognized as a denial of service attack. Then, to collect data at highest possible resolution, we gradually increased connection intervals and realized that 5-second data query does not create any connection. Hence, we prefer to collect data at this resolution.

Moreover, demand database table has five attributes, namely, "CountryCode", "TimeStamp", "DemandValue", "TempVal", and "Flag". The website publishes data for five GCC states", and also the aggregated demand in GCC. For the case of Qatar "CountryCode" is "QAT", while "TimeStamp" format is DD/MM/YY, HH:MM:SS. "DemandValue" is the real-time demand value in Mega-watts (MW). Moreover, the website provides temperature value and the data is stored under "TempVal". As we will discuss in the next section, in this paper, we prefer to use one-minute resolution data, and keep five-second resolution dataset for future research use. Hence, the last attribute "Flag" is "m" for minute resolution and "s" for five-second resolution. The program searches for the keyword "qat-mw-val" and grabs the value next to it. A Sample data collected from the website is shown in Table 3. Moreover, the overall infrastructure is depicted in Figure 1.

\footnotetext{
${ }^{2}$ Keyword comes from the way the website and supporting functionalities are coded. Keywords for other countries are in a similar format: for KSA the keyword is "ksa-mwval", for Kuwait, the keyword is "kuw-mw-val"

${ }^{3}$ Sultanate of Oman has not been connected and the demand value is always zero.
} 


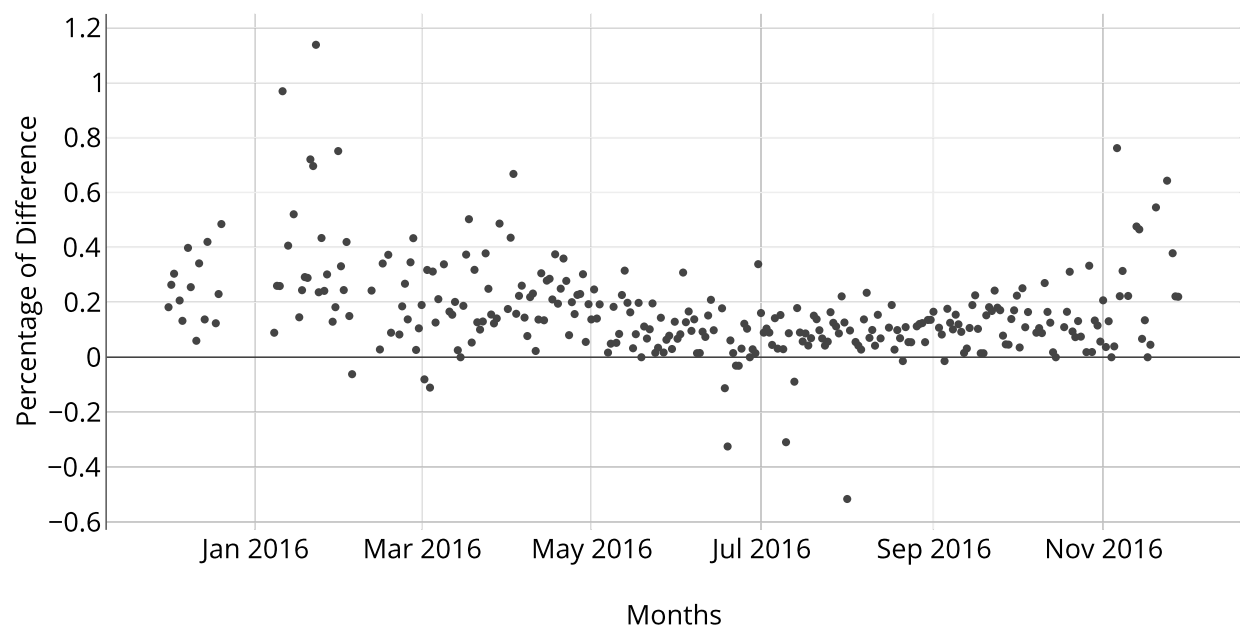

Figure 2: Comparison of 1-min dataset and actual data posted by the utility company.

\subsection{Data Validation}

Although GCCIA website is the sole official authority and the data published on the website [33] is expected to be accurate, we intend to further validate our dataset with the limited available statistics published by local authorities. The dataset presented in this study is from February 2016 to January 2017 and covers a twelve month period.

For the same time period, Qatar's public utility company, Kahramaa, posted the peak electricity consumption of certain days using their social media account ${ }^{4}$ [36]. For validation, we downloaded the published peak consumption data from Kahramaa's social media account. Next, for the same days, we retrieved peak consumption data from our 1-min resolution dataset and compared the two sources. As presented in Figure 2, the difference between our dataset and the Utility's data is mostly less than one percent. Therefore, we concluded that one-minute is a good resolution and it is used in our analysis in the next section. The second validation is based on comparing our dataset with the total monthly electricity demand statistics provided

\footnotetext{
${ }^{4}$ The title of the posts are "Daily electricity and water consumption figures. \#KAHRAMAA \#Qatar". A sample post can be seen at [35].
} 
Table 4: Comparison of Monthly Energy Consumption. All Energy Units are in MWh.

\begin{tabular}{lccccc}
\hline & Actual & \multicolumn{2}{c}{ 5-sec Res. } & \multicolumn{2}{c}{ 1-min Res. } \\
Months & Energy & Energy & Diff. (\%) & Energy & Diff. (\%) \\
\hline Jun'16 & 4277 & 4150 & 2.97 & 4153 & 2.90 \\
July'16 & 4801 & 4659 & 2.96 & 4660 & 2.94 \\
Aug'16 & 5036 & 4896 & 2.78 & 4890 & 2.90 \\
Sep'16 & 4509 & 4520 & -0.24 & 4381 & 2.84 \\
Oct'16 & 3758 & 3659 & 2.63 & 3651 & 2.85 \\
Nov'16 & 3071 & 2976 & 3.09 & 2971 & 3.26 \\
\hline
\end{tabular}

by the Qatar Ministry of Development, Planning and Statistics (MDPS) [32]. We compare the monthly energy of our dataset and the posted data in Table 4. The slight differences in the comparisons are because the data is collected at each minute, but the demand varies in real-time. For instance, on July 18, 2017 (no specific time mentioned), the peak consumption data published by Kahramaa is $7410 \mathrm{MW}$. On the same day, the highest demand recorded in 1-min database was $7400 \mathrm{MW}$ at 1:19 PM and the peak value in 5-sec database was $7407 \mathrm{MW}$ at 1:19:22 PM. This is depicted in Figure 3. Moreover, due to technical issues such as network outages or website issues, the dataset includes missing demand data. To that end, if the missing data is less than thirty minutes, we interpolate missing data. Otherwise, the entire day is excluded. Hence, such issues also lead to the difference between the actual data and the collected ones. In this study, we preferred to work with one-minute resolution dataset because compared to current literature where hourly data is mostly used, it provides good accuracy and the size of the dataset is manageable as opposed to five-second database.

\section{Results and Analysis}

\subsection{Seasonal Profiles and Peak Consumption}

In this section, we analyze high-resolution electricity load profiles, discuss and show, with case studies, how such data can be useful in research activities and daily system operations. From the power systems economics standpoint, it is important to know seasonal demand patterns, peak duration, and magnitude of peak consumption. Analyzing consumption patterns enable utility 


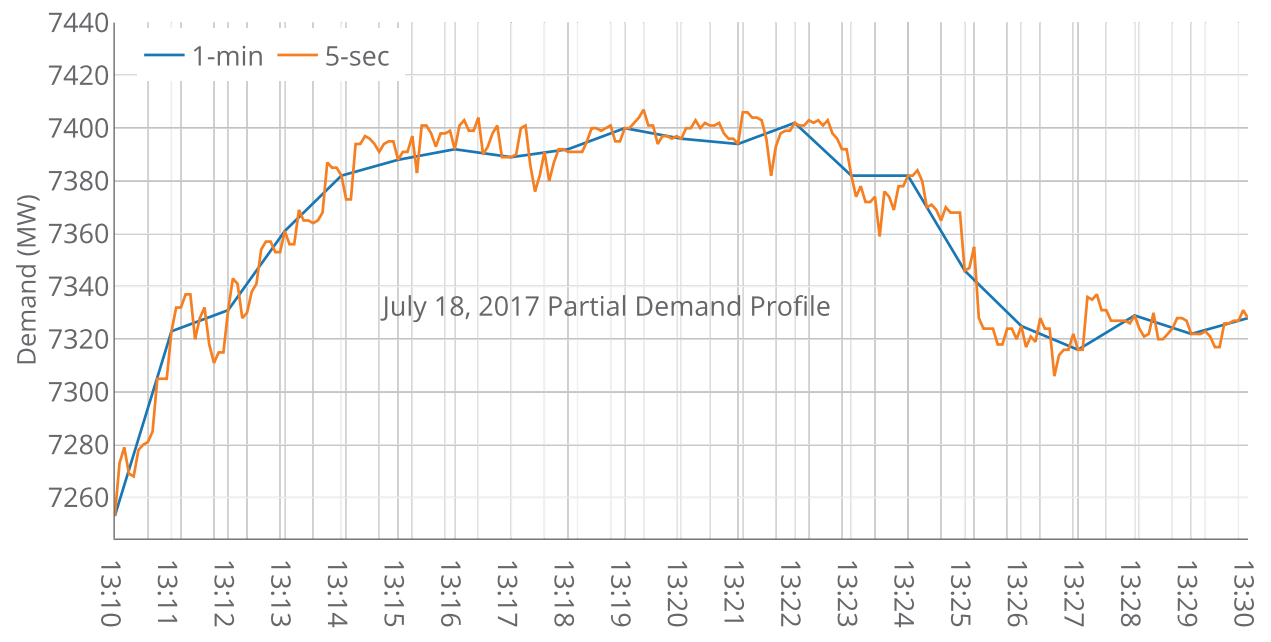

Figure 3: Comparison of 1-min and 5-sec data during July 18, 2017.

operators to prepare their generators, schedule maintenance, and plan system upgrades, if necessary. Similarly, independent power producers develop strategies to bid on the energy market. As a first step, in Figures 4 and 5, we present daily load profiles that are grouped by each month. Notice that, 346 days were analyzed and remaining 19 days were removed due to inability to collect data for several hours because of a network and/or power outage that affected our database.

In the figures, vertical axes are set at the same range, from $2000 \mathrm{MW}$ to $8000 \mathrm{MW}$, to better show how demand patterns vary at each month. It can be easily observed that electricity demand is low (one-third of the generation capacity) during winter months, e.g., December, January, and February, while April and November are the transition months. Electricity demand quickly increases during April due to rising temperatures and decreases during November as the average daily temperatures are below $25^{\circ} \mathrm{C}$. Summer months, on the other hand, are the peak months, the system utilization increases significantly, and the electricity demand is mostly more than two and half times higher than the winter periods. Moreover, summer peaks occur during afternoons, e.g., 1 pm to 4 pm, due to air conditioning load, while winter peaks occur during evening time due to lighting, cooking, and other activities. Such insights are critical in designing pricing strategies or other demand reduction policies to tackle the rising peak demand [37]. For instance, summer peak prices can be in the afternoon, while winter peak prices 


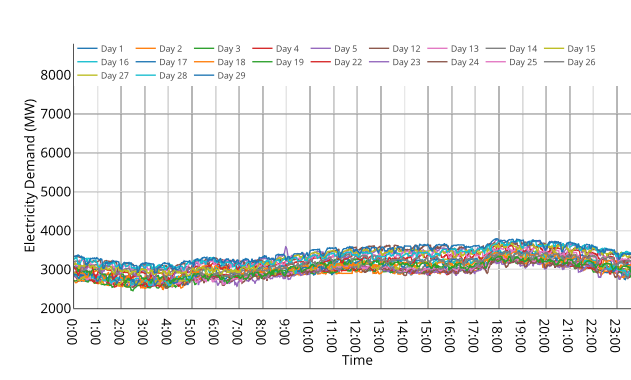

(a) February 2016.

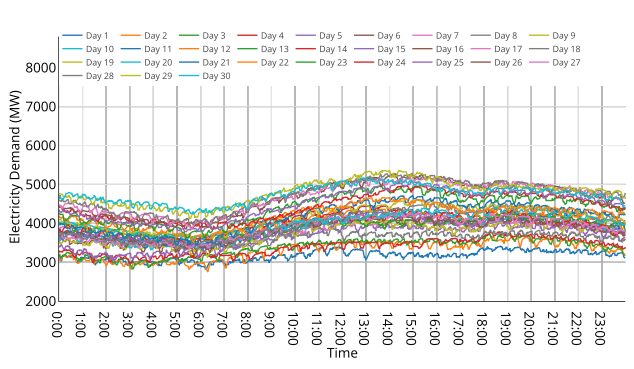

(c) April 2016.

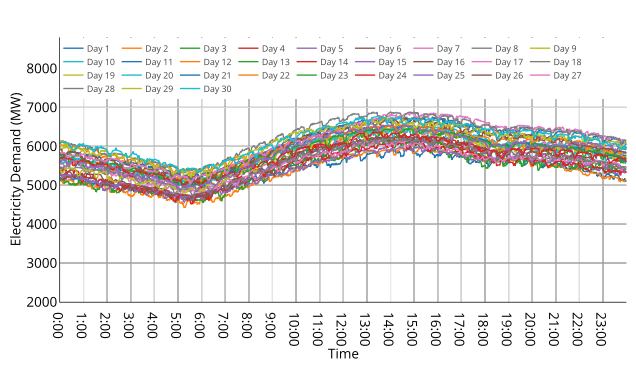

(e) June 2016 .

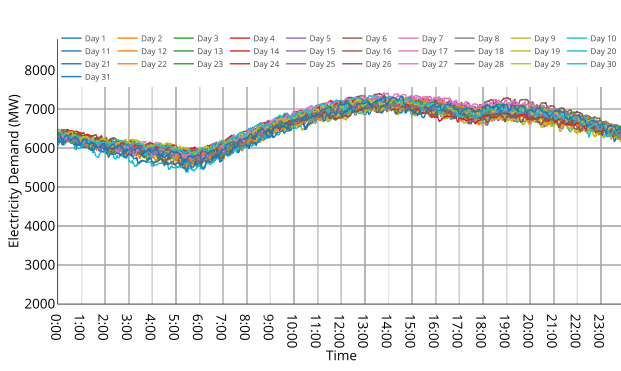

(g) August 2016.

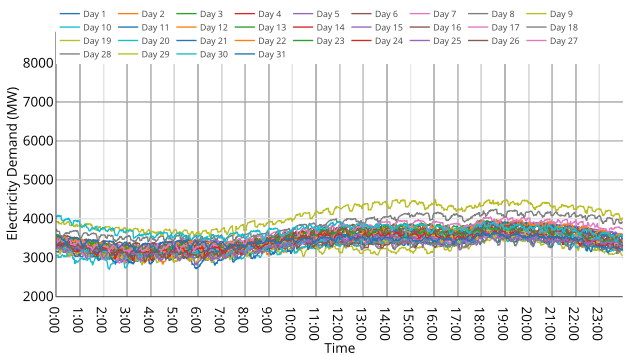

(b) March 2016.

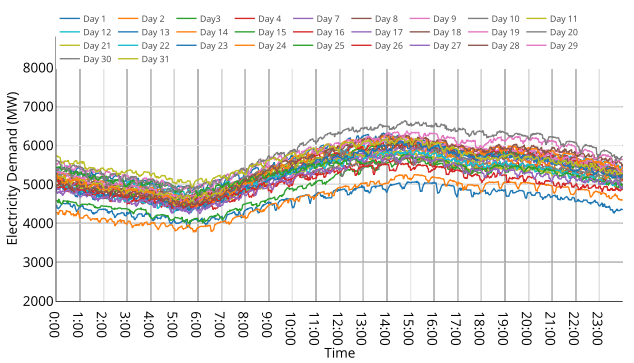

(d) May 2016.

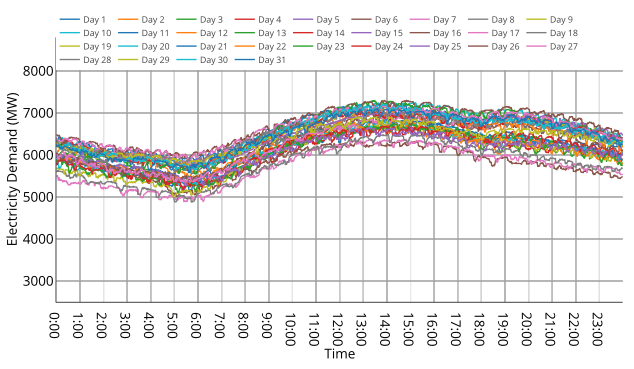

(f) July 2016.

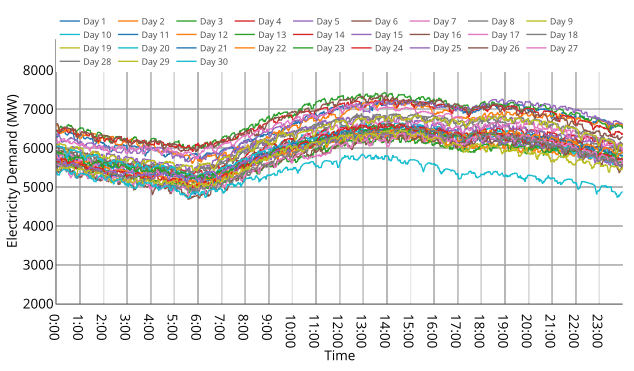

(h) September 2016.

Figure 4: Daily load profiles 1. 


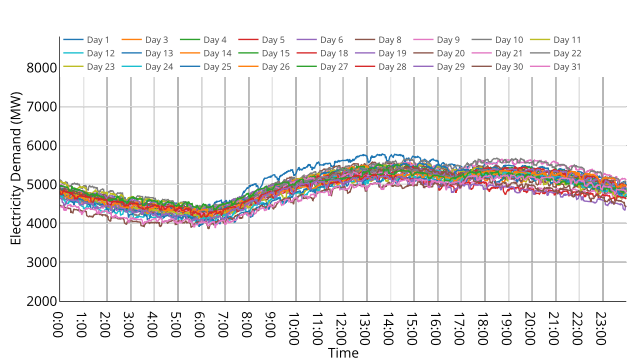

(a) October 2016.

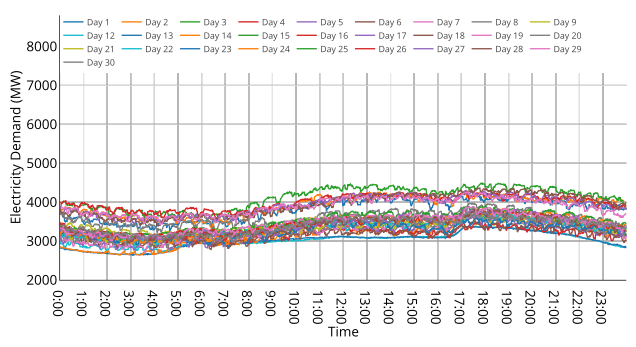

(c) December 2016 .

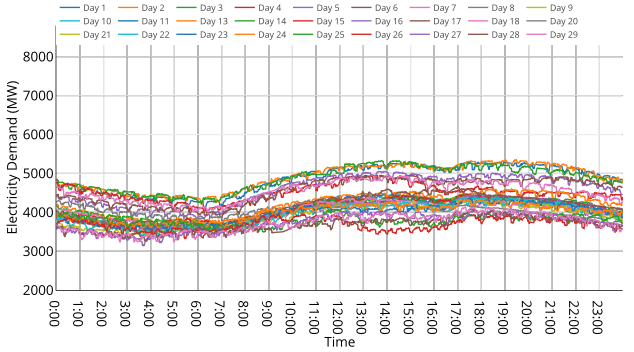

(b) November 2016 .

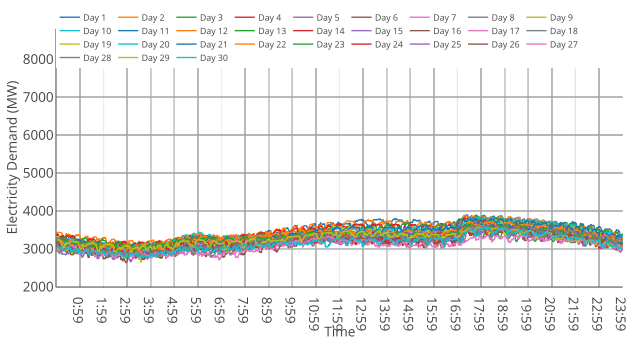

(d) January 2017.

Figure 5: Load profiles 2. 


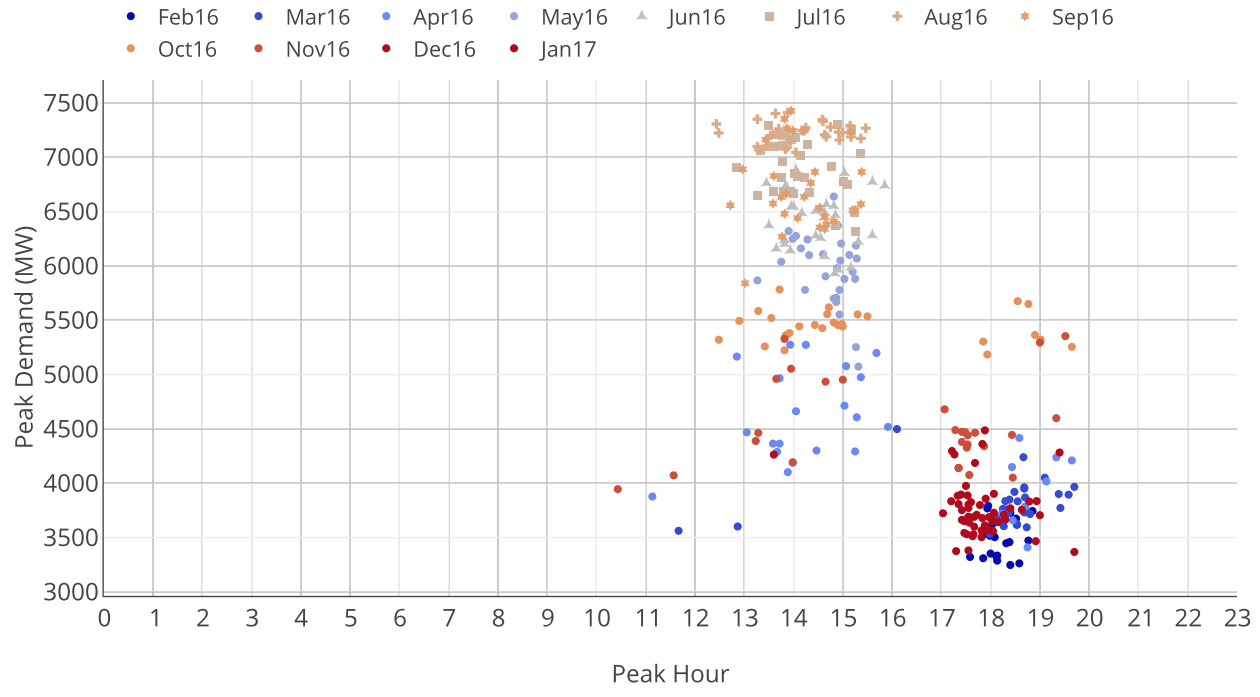

Figure 6: Peak demand and peak hour.

can be during evenings, while unit electricity cost could also be higher during summer. An overview of peak hours and magnitudes are presented in Figure 6. Furthermore, maximum, minimum, and average peak demand of each month is shown in Table 5. Another important indicator is the load duration curve which represents the power generation utilization. In Figure 7 , we present load duration curve and the histogram of the system load. For instance, the system demand exceeds top $97 \%$ of the peak demand, which is more than $7055 \mathrm{MW}$, for 45 hours, while more than $99 \%$ of the peak demand was used for 4.23 hours during twelve months period. Such insights are critical for determining the capacity of spinning reserves that are used in sudden demand surges.

The translation of seasonal profiles is multifold. First, as mentioned in Section 3.2, Qatar is a part of GCC interconnection network, therefore, surplus capacity during winter months can be exploited to sell electricity to neighboring countries. Second, peak electricity consumption occurs during summer afternoons due to the cooling load. Hence, demand response programs should focus on addressing such loads. Considering the fact that electricity prices are subsidized and average household disposable income is remarkably high in Qatar, differential pricing may have limited impacts. In 
fact, in our previous study [1], we showed that doubling electricity tariffs in Bahrain, a neighboring country with similar socioeconomic characteristics, have limited impacts during summer months, while sizable reductions were observed during other months. Similarly, a dynamic pricing study conducted in Florida, a state with hot and humid climate, shows that the peak reduction during winter months is higher than the summer months simply because the residents do not like to sacrifice cooling comfort for monetary savings [38]. However, direct load control mechanisms can be a stronger solution as cooling systems consume a significant portion of residential loads [2]. In such programs, AC units are shut down or set temperatures increase by a few degrees during peak consumption times for a limited duration.

An illustrative empirical study is presented next. We deployed an energy monitor, thermal and hygrometers at a typical two bedrooms two-story Qatari villa with a total physical space of 219 square meters. To measure the magnitude of air conditioner load, we shut down the AC unit for 15 and 30 minutes and recorded the power demand and the indoor climate. As seen in Figure 8, daily electricity load is dominated by the cooling load during a typical summer afternoon and 11-12 $\mathrm{kW}$ of demand can be saved by DLC in this particular house. The temperature rise during was experiment less than $2^{\circ} \mathrm{C}$ which was acceptable by the occupants and there was no major change in relative humidity ${ }^{5}$. It is important to note that during the time when we conduct the experiments, the outdoor temperature was around $50^{\circ} \mathrm{C}$. As shown in Figure 8, before and after the DLC event, AC unit worked at full capacity as it can barely reach the set point. Therefore, the same amount of power continued to be consumed after the DLC event. However, if the experiments were conducted during a mild day (i.e., $35-36^{\circ} \mathrm{C}$ ), then we would expect $\mathrm{AC}$ unit to consume more energy to compensate temperature rises. Obviously, to better estimate DLC potential at a nation-level, a similar study needs to be done at various houses with different sizes. It is noteworthy that demand reduction potential per house in Qatar is significantly higher than the United States or Canada (less than $1.5 \mathrm{~kW}$ per household [39]) and DLC can have significant impacts on power system operations. Moreover, Qatari residents take extended summer holidays, but they keep their air conditioning units running. Such cases can be exploited and AC units can be cycled even for longer durations.

\footnotetext{
${ }^{5}$ Temperature raised from 22 to $24^{\circ} \mathrm{C}$, while humidity was $60 \%$
} 


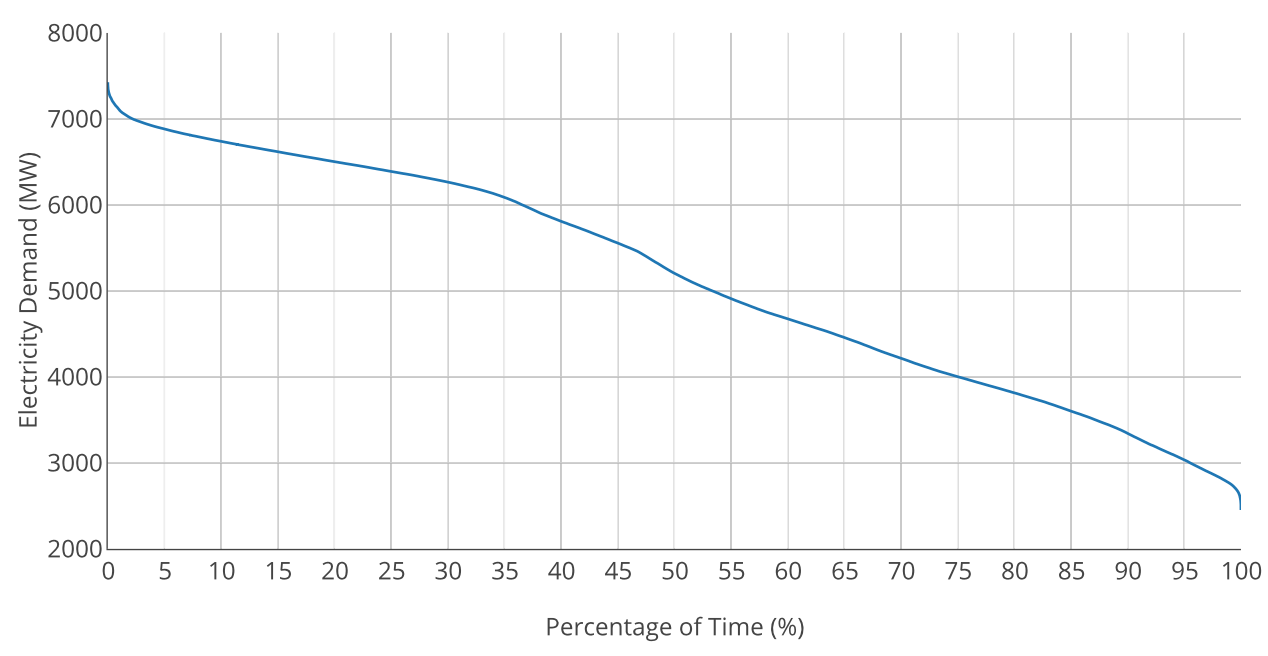

(a) Load duration curve.

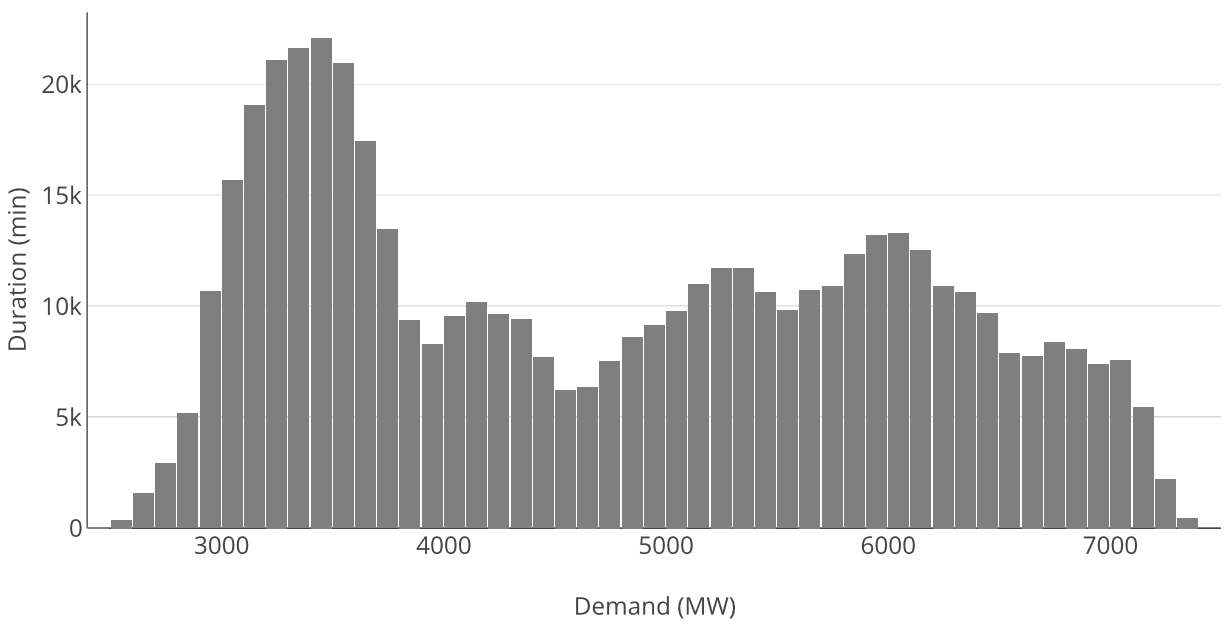

(b) Histogram of system load.

Figure 7: Time-magnitude analyses of system load. 


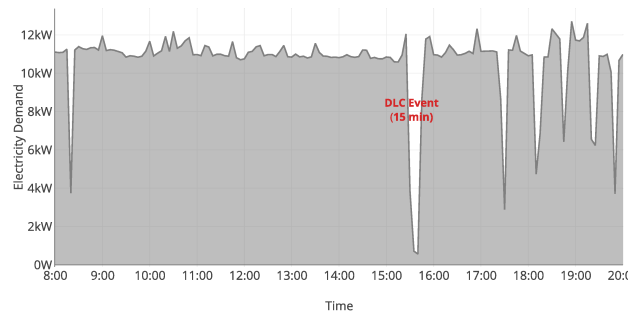

(a) August 12, 2017.

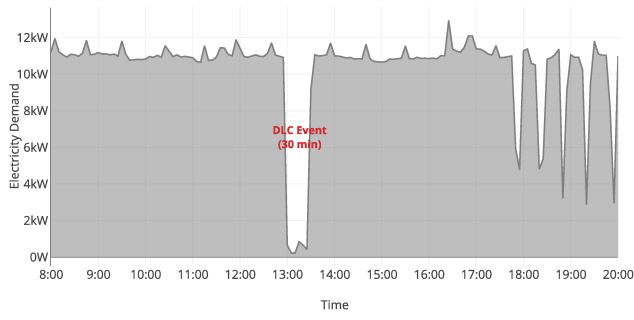

(b) August 13, 2017.

Figure 8: Direct load control experiments at a Qatari villa.

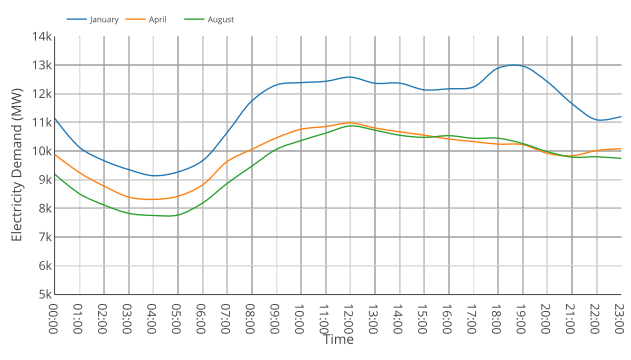

(a) Belgium.

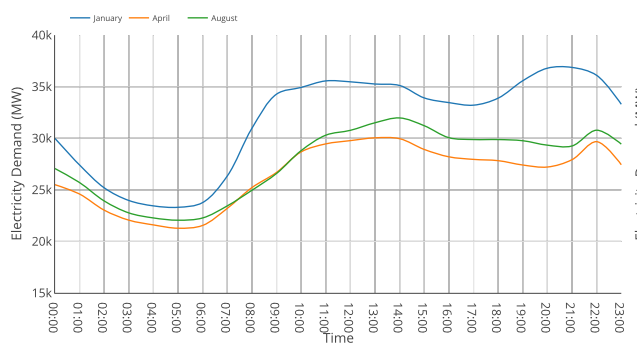

(c) Spain.

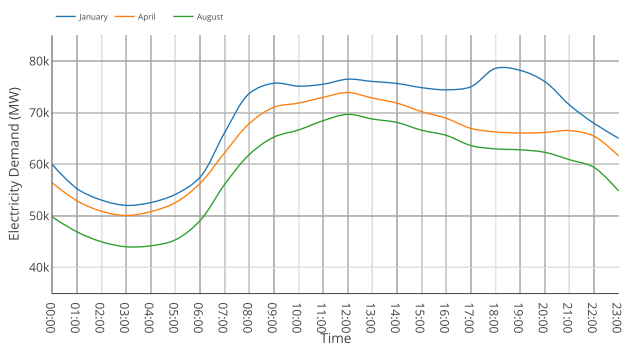

(b) Germany.

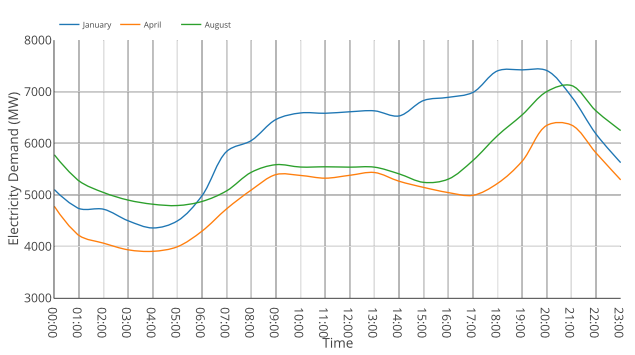

(d) Greece.

Figure 9: Sample hourly load profiles in selected European countries [40] . 
Last, Qatar's load profiles differ significantly from most countries due to the nature of the country. Typical profiles used in the current research varies throughout the day and includes a noticeable peak consumption at night (sometimes in the morning) and the difference between the seasonal profiles are moderate. On the other hand, a typical summer day demand can be three times higher than an average winter load. Daily load factors (DLF) are regarded as a good metric to show the consumption patterns during the day and calculated based on the formula below

$$
\operatorname{DLF}(\%)=\frac{\text { Electricity Generation in a Day }}{\text { Peak Demand of the Day } \times \text { Total No. of Hours in a Day }} \times 100
$$

The statistics for daily load factors in Qatar for each month is presented in Table 5. For instance, on February 26, 2016, the peak demand was 3458 MW, while total energy consumption was recorded as 76013.82 MWh. By plugging these numbers into equation $(2)^{6}$, DLF is calculated as $91.59 \%$. Similar calculations are made for each day of each month, and maximum, average, and minimum DLFs are presented in Table 5, along with daily peak demand. It can be seen that for most months, the average DLF is more than $90 \%$ which means that the consumption does not change substantially during the day. This is mostly due to subsidies, high income, and bulk power agreements between customers (including residential sector) and the utility company. To provide deeper insights, in Figure 9, we present sample daily load profiles from four different European countries in 2014. Each line represents the third Wednesday of January, April, and August ${ }^{7}$. It can be seen that seasonal demand differences are notable, but not as dramatic as the Qatari case. Therefore, research focusing on Qatar need to adjust the assumptions made for the local consumption behaviors.

\subsection{Load Curves and PV Integration}

Qatar is aiming to produce a significant portion of its electricity from renewable PV generation ${ }^{8}$. Recently, mid to large-scale integration of renewable energy resources into power grids have intensified the concerns with

\footnotetext{
${ }^{6}$ Total hours in a day is taken as 24 .

${ }^{7}$ Such months are chosen due to the availability of the data from European Network of Transmission system Operators for Electricity.

${ }^{8} 200 \mathrm{MW}$ by 2020 and 2 GW generation capacity by 2030 .
} 


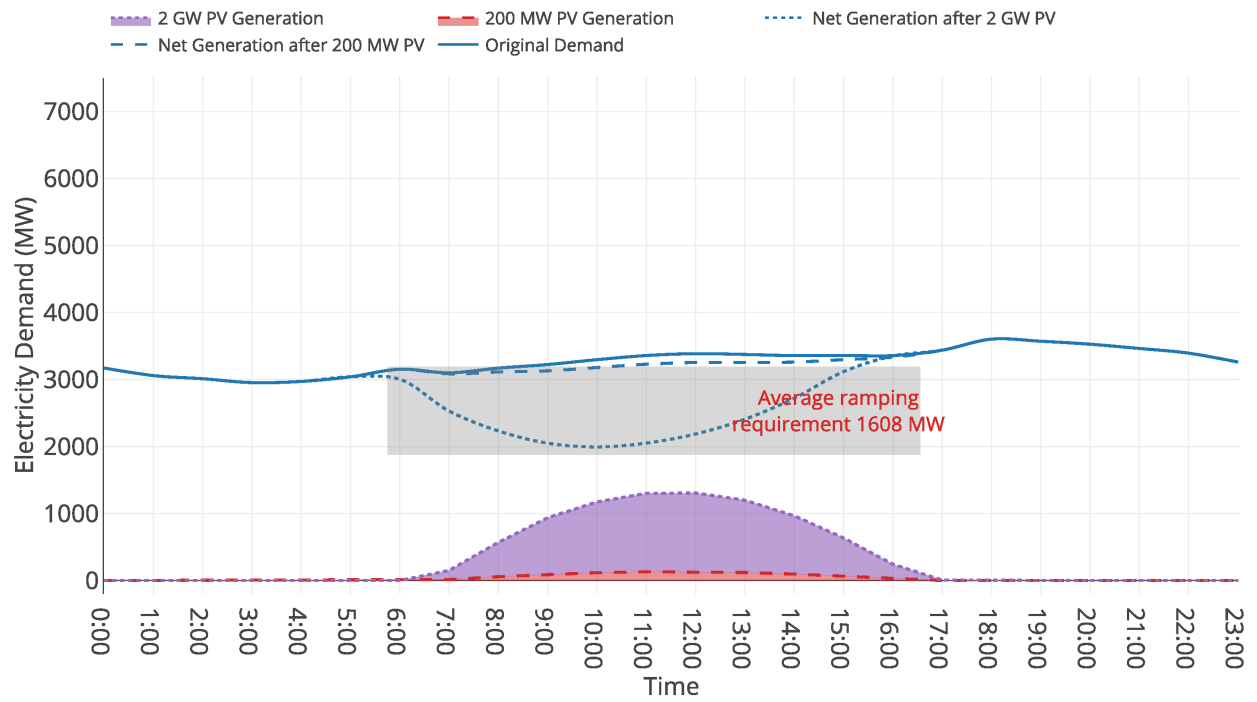

(a) January 2017.

2 GW PV Generation $\quad=200$ MW PV Generation

..... Net Generation after 2 GW PV

- - Net Generation after 200 MW PV — Original Demand

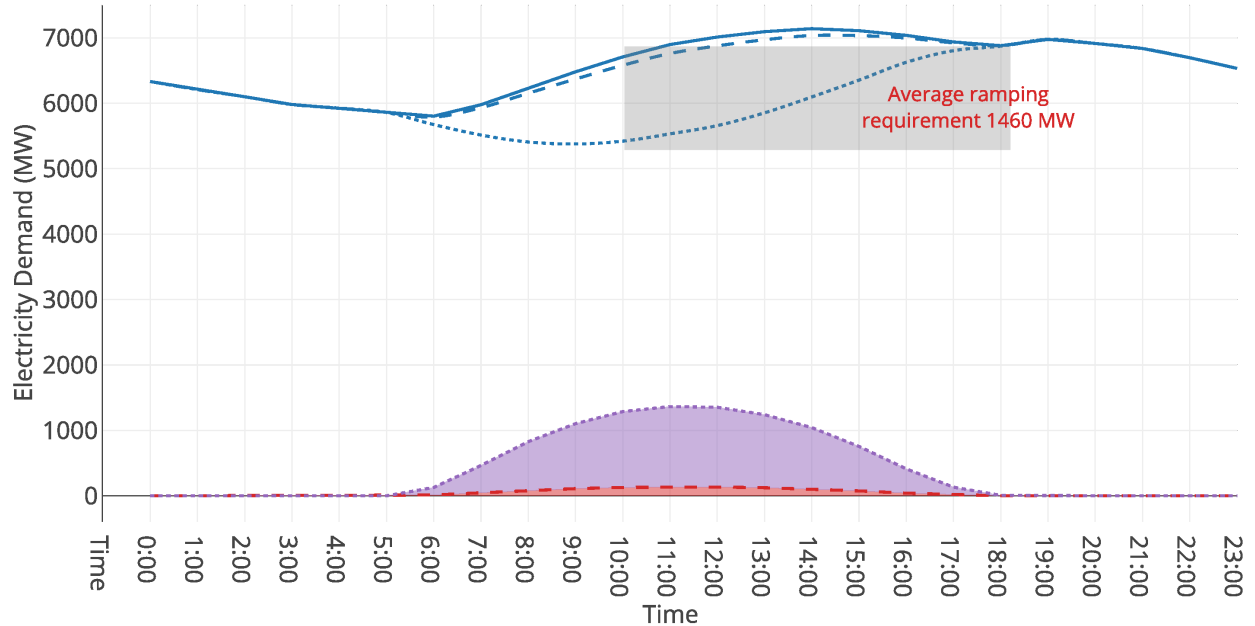

(b) August 2016.

Figure 10: Load profiles, duck curves, and ramping requirements. 
Table 5: Daily Load Factors and Daily Peak Demand.

\begin{tabular}{lcccccc}
\hline & \multicolumn{3}{c}{ Daily Load Factor (\%) } & \multicolumn{3}{c}{ Daily Peak Demand (MW) } \\
Month & Max & Mean & Min & Max & Mean & Min \\
\hline Feb-16 & 91.59 & 89.10 & 86.80 & 3791 & 3491 & 3247 \\
Mar-16 & 93.94 & 90.76 & 88.82 & 4498 & 3816 & 3533 \\
Apr-16 & 94.11 & 90.39 & 88.16 & 5362 & 4430 & 3409 \\
May-16 & 91.85 & 88.98 & 86.55 & 6638 & 5968 & 5073 \\
Jun-16 & 91.07 & 89.79 & 87.77 & 6883 & 6424 & 5931 \\
Jul-16 & 92.36 & 90.92 & 89.01 & 7298 & 6898 & 6316 \\
Aug-16 & 92.28 & 91.06 & 89.93 & 7411 & 7217 & 7043 \\
Sep-16 & 92.50 & 90.68 & 88.83 & 7427 & 6710 & 5840 \\
Oct-16 & 92.20 & 90.24 & 88.77 & 5782 & 5441 & 5184 \\
Nov-16 & 93.63 & 91.32 & 87.98 & 5353 & 4543 & 3945 \\
Dec-16 & 93.08 & 90.09 & 85.62 & 4486 & 3853 & 3375 \\
Jan-17 & 91.44 & 89.47 & 88.21 & 3895 & 3659 & 3367 \\
\hline
\end{tabular}

the "duck curve" which is a term used to represent the net load curve after the renewable production is subtracted from the generation profile before the renewables. Recall that supply and demand should be balanced at all times. Therefore, for the case of high PV penetration, the output of the conventional generators such as natural gas, coal, and nuclear need to be adjusted due to high renewable output. However, when the PV production gradually decreases in the late afternoon, then, conventional generators should quickly ramp up their production to keep up with the demand [41]. If the flexibility of the generators is not adequate, then, the system may encounter over-generation. Note that power generation flexibility, which is usually measured by ramp rate, the rate at which the power plant can increase or decrease its output and measured in MW per minute, plays a critical role. This is particularly a problem in countries with inflexible generators such as nuclear and coal since shutting down such generators are costly and timeconsuming. Hence, system operators prefer to pay customers to consume electricity rather than taking generators off-line and experience economic losses [42]. Therefore, to address the potential issues with the duck curves, system operators need to consider (1) load profiles, (2) PV output, and (3) the flexibility of the generators.

In order to provide insights into how load curves can be used to ad- 
dress "duck curve" phenomenon, we provide two case studies. We simulate a 200 MW and a 2 GW PV farm in Qatar using System Advisor Model (SAM) Platform developed by National Renewable Energy Laboratory (NREL) [43]. Input parameters such as global horizontal irradiance (GHI) and other meteorological variables are adopted from [19], which presents the results of a ground measurement station located at Hamad Bin Khalifa University. Simulations are performed for August and January, to mimic two different seasons in Qatar. Results depicted in Figure 10 show how the generation output would change when $200 \mathrm{MW}$ and $2 \mathrm{GW}$ PV farms are integrated into the power grid in Qatar. For the case of $2 \mathrm{GW}$ penetration, it can be observed that average ramping requirement during January is higher than the ramping requirement in August. One of the reasons is that during winter peak demand occurs at night, while summer peaks are in the afternoons and coincide with PV generation. It is also important to note that for natural-gas turbines to reach advertised ramping rates, turbines should reach a self-sustaining speed which could take around 30 minutes to satisfy that condition. Because the utilization of generators is low during winter, PV penetration could be problematic and needs to be addressed holistically. To do so, high-resolution simulations need to be performed and the readiness of Qatari power grid can only be assessed if actual power plants parameters are known. Notice that power generation is entirely based-on natural gas. Each time a power planed is cycled, e.g., turned on or off, steam lines, boiler, turbine, and other parts experience large thermal stress which causes damage and degrade the cycle-life the generators.

In addition, PV panels can be deployed at customer premises typically at rooftops. In such systems if the PV production is higher than domestic consumption, then, the excess power is fed into the power grid. Large scales of PV penetration would cause voltage deviation and reactive power problems due to intermittencies associated with PV output. For instance, the acceptable voltage deviation limit is usually within $+5 \%$ and $-5 \%$ of the rated levels (e.g., $230 \mathrm{~V}$ for Qatar). To accommodate PV penetration, distribution operators employ storage units or capacitor banks to maintain desired power flow. For the case of Qatar, demand measurements presented in Figure 10 shows that most of the PV production in summer will be consumed locally, as the time of generation and consumption coincide. Hence, the distribution network is not expected to be negatively affected. However, when the consumption during winter months drops significantly, then, the grid may experience voltage deviations [1]. As a future work, we will conduct a thorough 
investigation and address a variety of cases related to PV integration.

\subsection{Mathematical Modeling and Load Forecasting}

As the bulk storage of electrical energy is still not economically viable, it is important accurately model and forecast electricity loads typically for three distinct time horizons: (1) short-term which is from one hour to one week, (2) medium-term forecasts that are from one week up to a year, and (3) long-term forecasts for longer than a year. Accurate forecasting models have immediate economic impacts on power system operations as load forecasting is essential for critical decisions on purchasing and generating power, load switching, and infrastructure development. Some of the most commonly used methods are regression models, neural networks, statistical learning techniques, time series, and expert systems [9]. In all modeling and forecasting techniques the most critical input is load profiles, while time, weather, and customer classes are also employed. Time-related factors could be the time of the year, the day of the week, or hour of the day. For instance, in literature, weekends and weekdays are known to exhibit different consumption patterns. Similarly, the electricity consumption typically reduces during public holidays. In Figures 11 and 12, we present monthly averages of weekdays and weekends. Notice that in Qatar weekends are Fridays and Saturdays, while weekdays start on Sundays and ends on Thursdays. It can be observed that the difference between consumptions during weekends and weekdays are not very high. One of the main reasons, particularly for summer months, is that cooling load does not change throughout the week. In addition, in Figure 13, we compare public holidays with the average load on the month that it took place. Unlike the previous case, the consumption patterns significantly decrease during public holidays as a sizable portion of the residents go abroad for vacations. Holidays need to be carefully taken into account for load forecasting and PV integration due to sudden changes in the consumption patterns.

Temperature, relative humidity, and heat index are most commonly used weather-related parameters ${ }^{9}$. To show the correlation between meteorological variables and the electricity demand, we use data collected by the weather station located at Hamad Bin Khalifa University campus. Data contains oneminute resolution temperature and relative humidity [19]. In Figure 14, we

\footnotetext{
${ }^{9}$ Cooling degree days, heating degree days, and dew points are also used in the literature.
} 

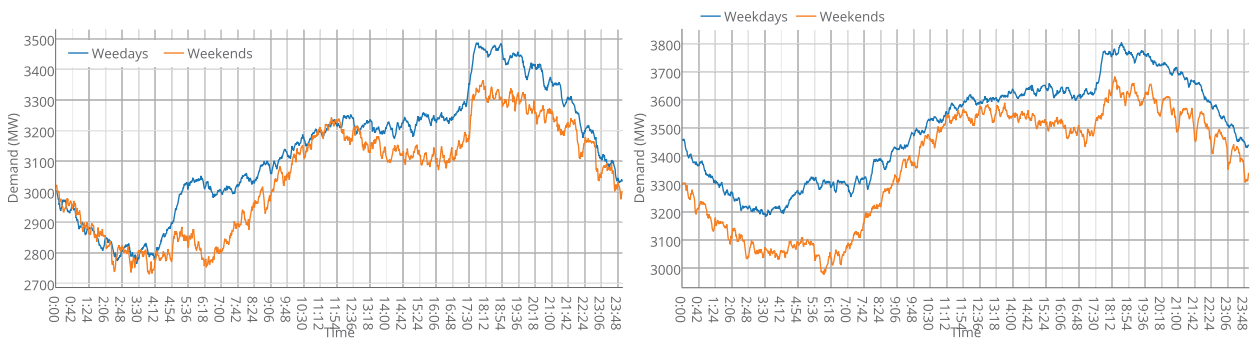

(a) February 2016 (ave. diff.=2.54\%). (b) March 2016 (ave. diff.=3.67\%).
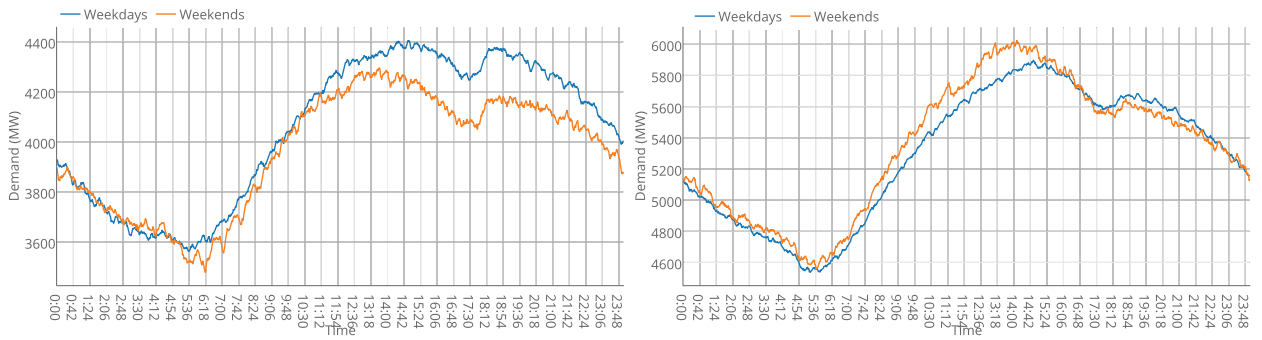

(c) April 2016 (ave. diff. $=1.99 \%$ ).

(d) May 2016 (ave. diff. $=0.96 \%$ ).
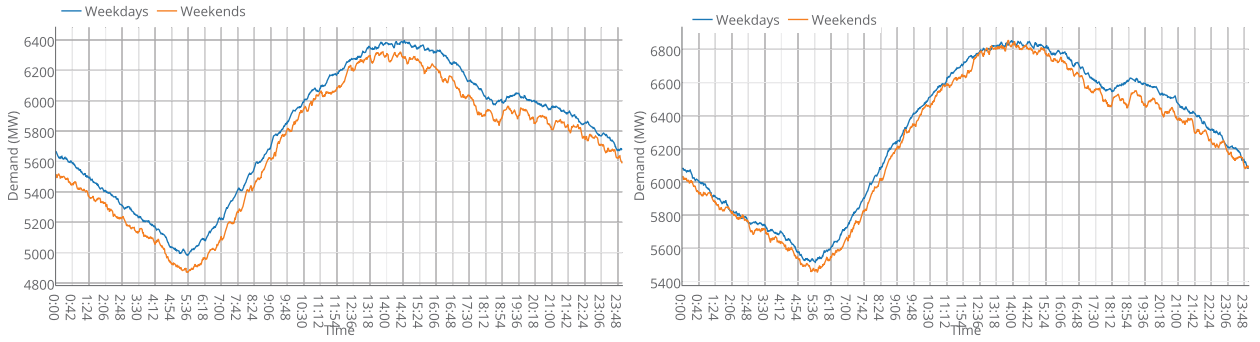

(e) June 2016 (ave. diff. $=1.72 \%$ ).

(f) July 2016 (ave. diff. $=0.84 \%$ ).

Figure 11: Average weekdays and weekends load profiles and average difference (ave. diff.). 

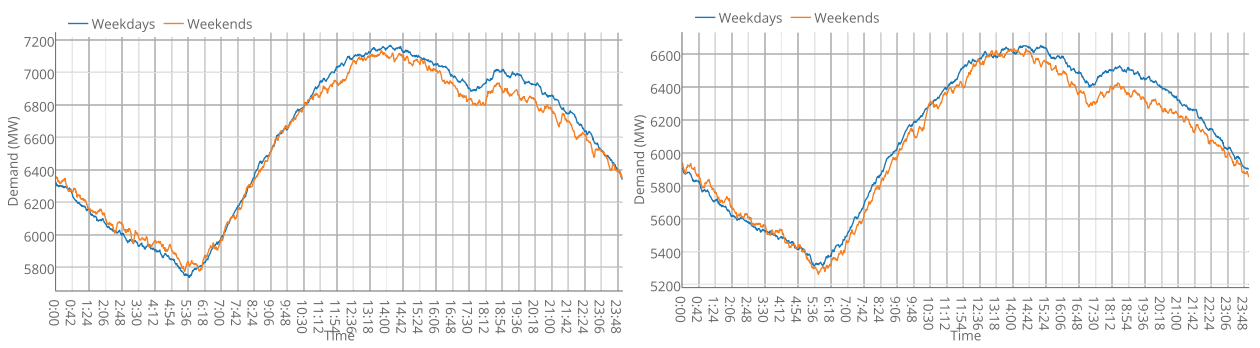

(a) August 2016 (ave. diff.=0.38\%). (b) September 2016 (ave. diff. $=0.74 \%$ ).
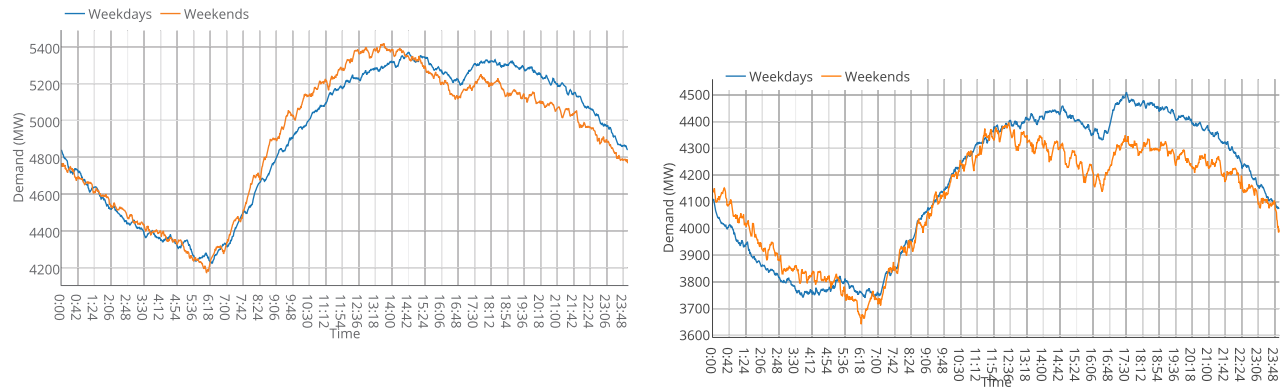

(c) October 2016 (ave. diff. $=0.12 \%$ ).

(d) November 2016 (ave. diff.=1.11\%).
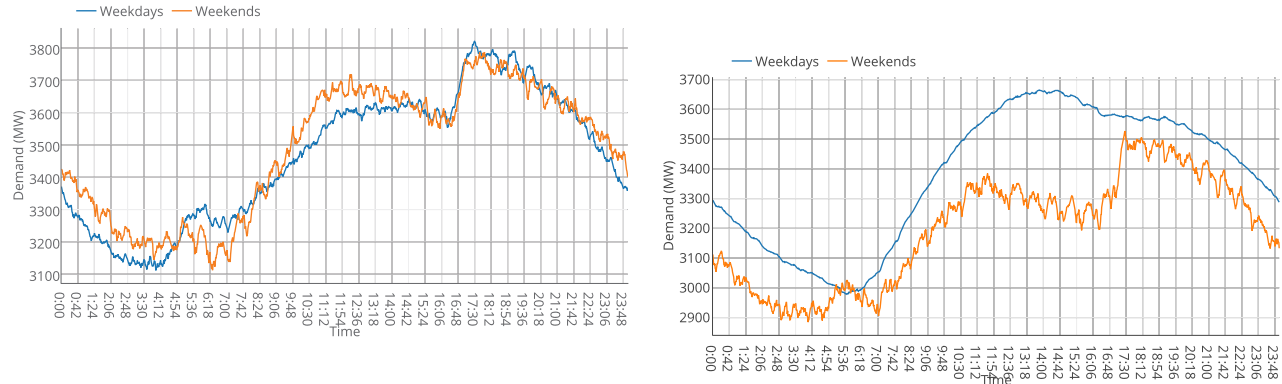

(e) December 2016 (ave. diff.=0.64\%). (f) January 2017 (Ave. Diff=5.21\%).

Figure 12: Average weekdays and weekends load profiles 2 and average difference (ave. diff.). 


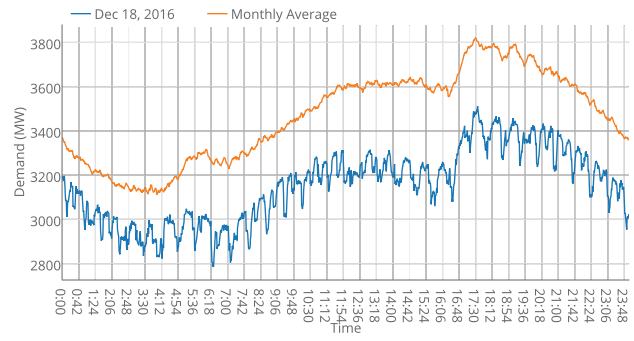

(a) Qatar National Day.

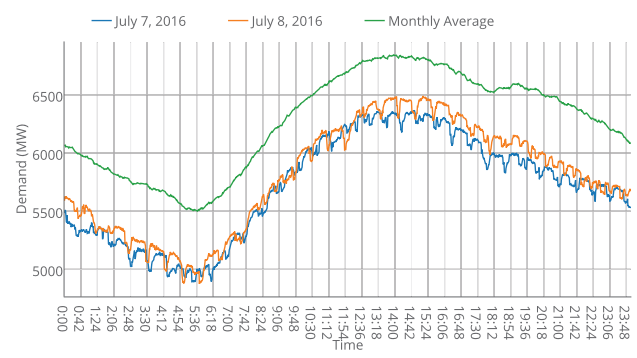

(c) Eid Al-Fitr holiday.

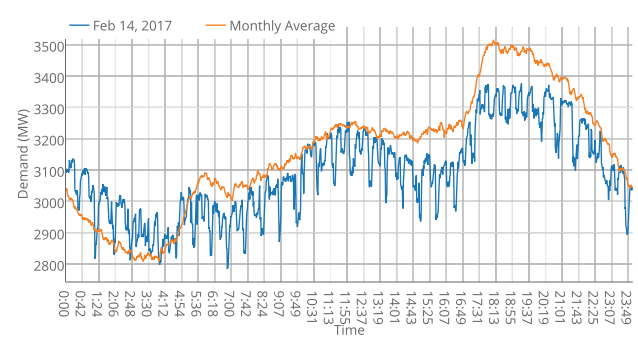

(b) Qatar Sports Day

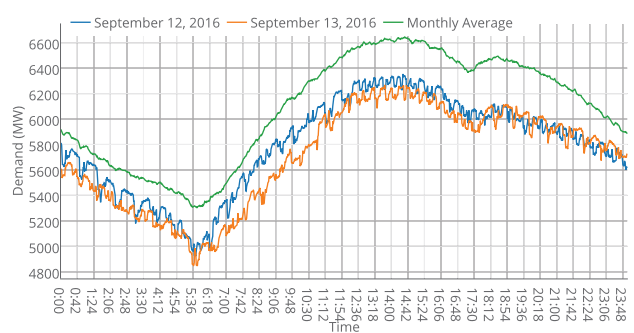

(d) Eid Al-Adha holiday.

Figure 13: Comparison of public holidays with the average monthly consumption.

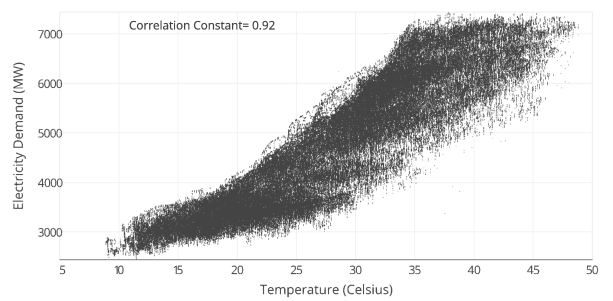

(a) Demand vs. temperature.

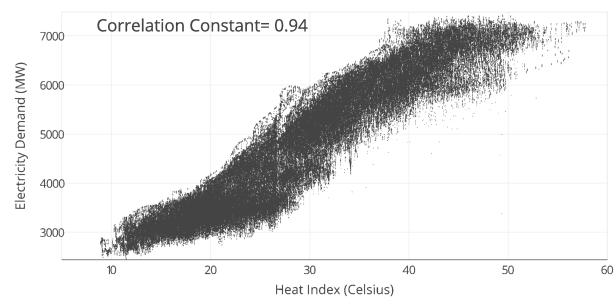

(b) Demand vs. Heat index.

Figure 14: Correlation between electricity demand and temperature is $92 \%$, while it is $94 \%$ for heat index. 


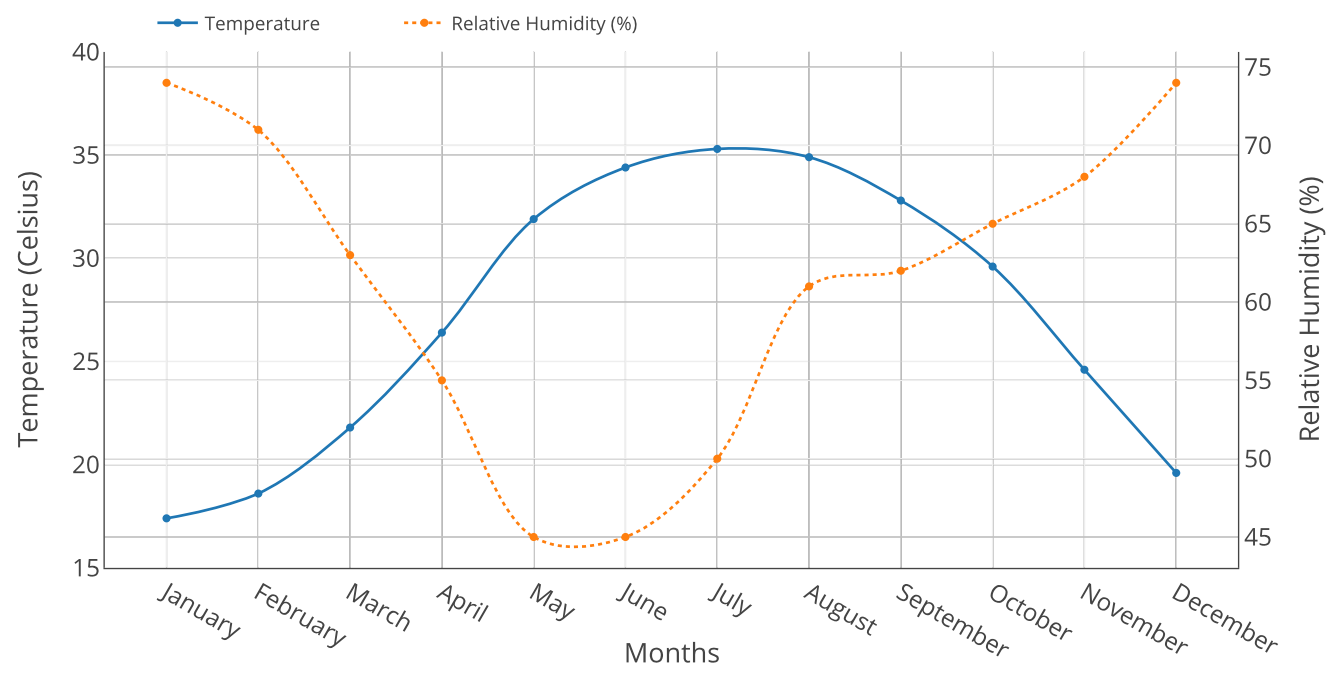

Figure 15: Long-term monthly average temperature and humidity values [4]

present the correlation between (1) electricity demand and temperature and (2) electricity demand and heat index. Notice the correlation between temperature and demand is $92 \%$, while heat index correlation is $94 \%$. Another commonly used parameter is the cooling degree days which is the difference between hourly temperature and a base value such as 65 Fahrenheit that represents the threshold value above which people use air-conditioning. The correlation between monthly energy consumption and monthly CDD is calculated as 0.986 , which further supports our initial findings.

\section{Estimation of Air-conditioning Load}

The results and discussions given in the previous section indicate that electricity consumption is dominantly driven by cooling load. To further highlight this point, in Figure 15 we present long-term (1990-2013) average monthly temperature and humidity values which were collected from Qatar Meteorology Department[4]. Notice that electricity consumption patterns shown in the previous section follow a similar order with weather data. As discussed in the previous section direct load control techniques (or other demand-side management technologies) can be practical solutions to shave the peak demand. Therefore, knowledge of the amount of power that can be 


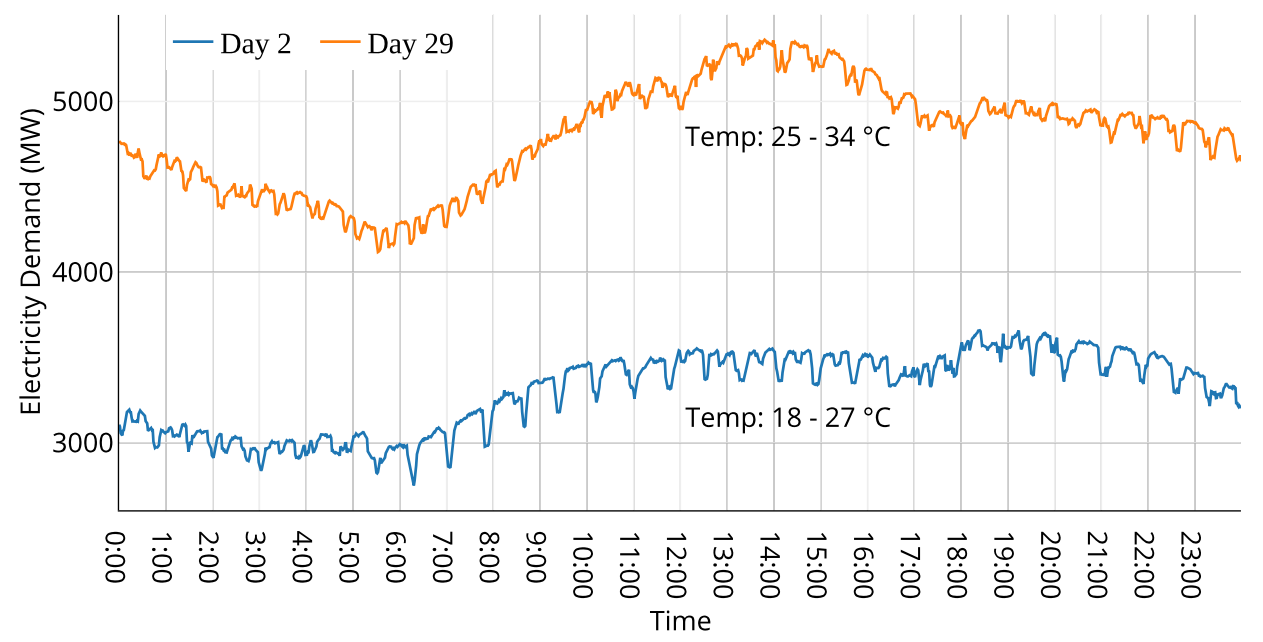

Figure 16: Load profile of two days in April 2016.

shifted or reduced is a prerequisite to design and evaluate the potential benefits of cooling-related demand-side management techniques. In this section, we propose a top-down methodology to estimate the cooling load using the electricity load profiles given in the previous section.

Our estimation is based on calculating the difference between a reference load profile which represents little or no cooling demand, and the rest of the days where cooling takes place. In order to choose non-cooling reference days, we considered days in which the average temperature is less than 65 Fahrenheit (or 18.3 Celsius). Recall that in literature this reference point is used to calculate cooling degree days (CDD) in which average customers start to use cooling systems $[44,45]$. The method we propose in this section is simple and reproducible and provides a good estimation of the cooling load. In addition to the correlation between consumption and weather parameters, several other factors support the accuracy of the proposed methodology. First, most of the population in Qatar reside in a physically well-confined region (approximately $11,437 \mathrm{~km}^{2}$ ), hence daily human activities throughout the country can be considered as the same. Second, total heating degree days during three winter months, December, January, and February, was only 24. Therefore, heating load during winter can be negligible. And last, the sunset hours 


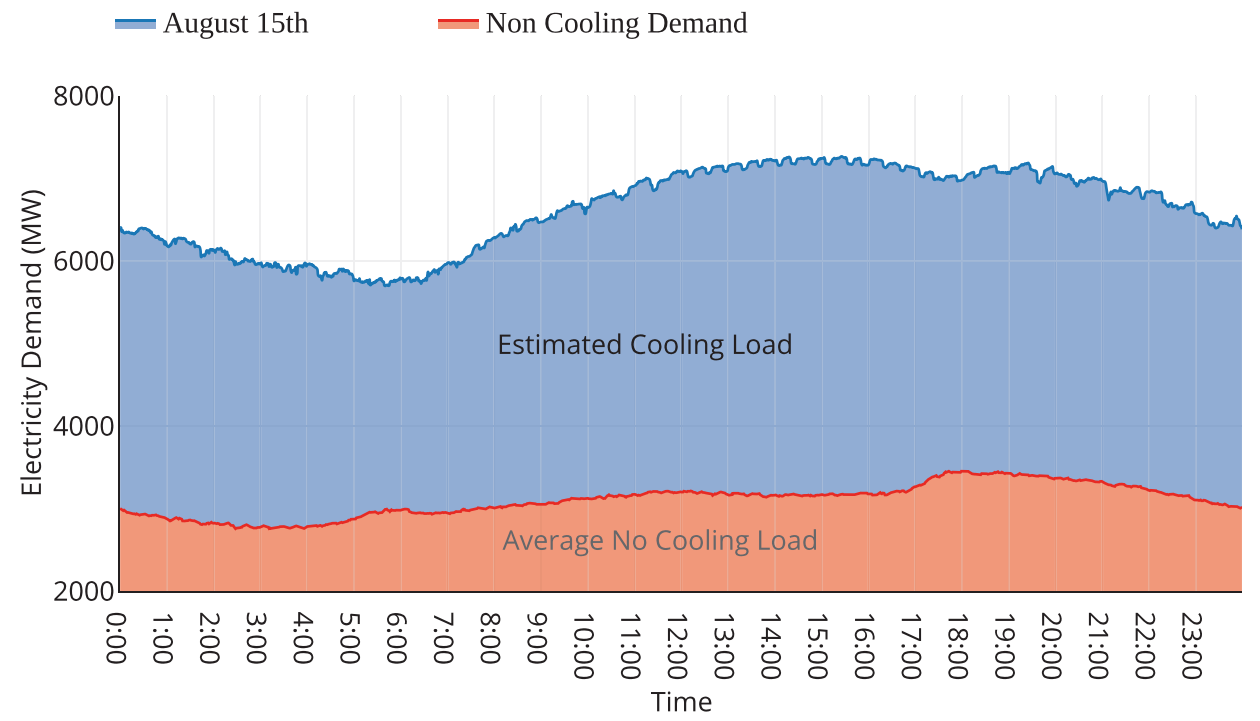

(a) Sample calculation of cooling load in August 15, 2016 .

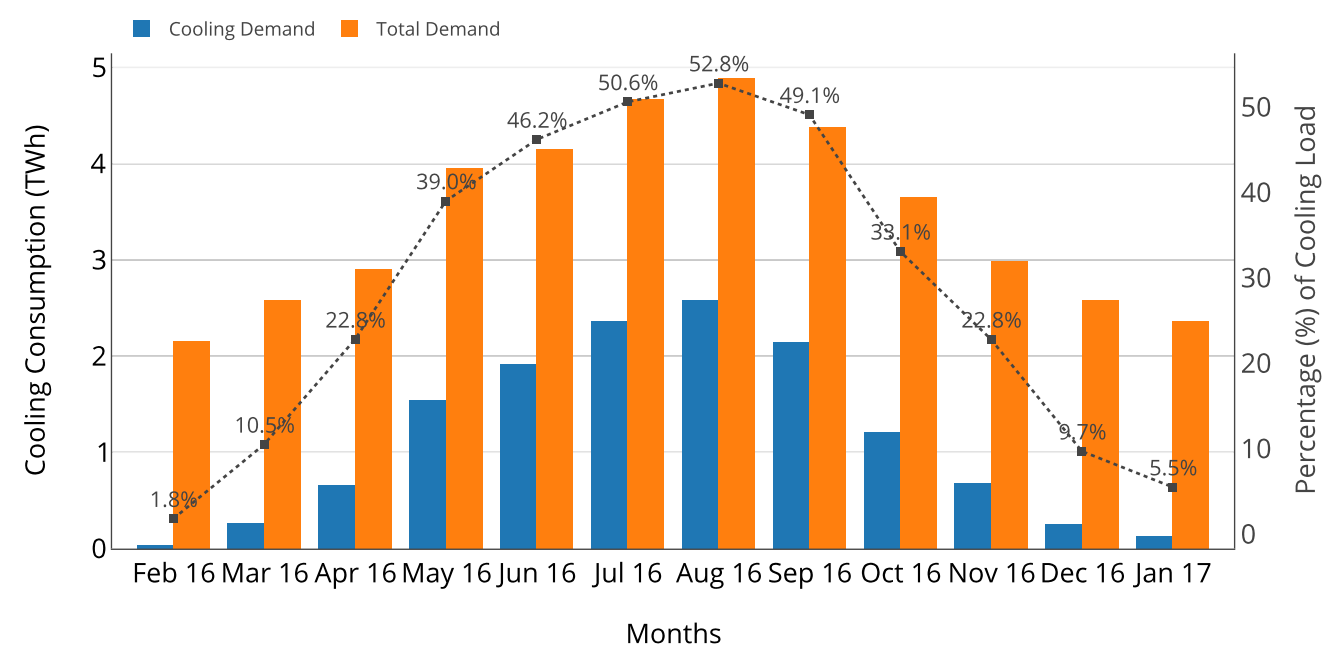

(b) Monthly cooling demand.

Figure 17: Cooling load calculations. 
vary at max one hour and forty-five minutes ${ }^{10}$. Therefore, the impacts of lighting load between the seasons are minimal. To illustrate this point, we present two daily load profiles from April 2016. As shown in Figure 16, electricity consumption almost doubles during the same month. Assuming that these two days are equivalent in all other factors (e.g., population, electricity prices, etc.), the dramatic difference between the two load profiles should be due to the cooling load.

Next, we identify non-cooling days: four days from December, ten days from January, and ten days from February are chosen and the average of total 24 days is taken. Then, each day is subtracted from the reference load profile. It is noteworthy that a similar method is used in [46] using hourly data in the United States. A sample calculation is presented in Figure 17a. In this figure, non-cooling load (red font) represents non-cooling load such as industrial load and residential loads other than cooling. Notice that since the difference between weekends and weekdays are insignificant, we choose to have one base demand pattern. The calculation presented in Figure 17a is repeated for each day of the year. In Figure $17 \mathrm{~b}$, we present monthly cooling demand estimates and the percentage cooling load respect to that month. It can be seen that nearly half of the demand during summer months is consumed for cooling purposes, while this proportion is low during winter months.

\section{Conclusion}

In this paper, we presented and analyzed the first high-resolution electricity load profile in Qatar and GCC region. The data collection platform consisted of a C-Sharp script that searches and retrieves data to a local MySQL database that organizes and stores consumption data. The data collection has been taking placing fore more than one and half years and the paper included a full year data. The load profiles showed that electricity consumption in Qatar follows a unique pattern: very high daily load factors indicate that electricity consumption does not change significantly during the day because of subsidized tariffs and high disposable income. Also, there is a considerable difference between summer and winter demand due to variation in temperature levels. Furthermore, with several case studies, we showed

\footnotetext{
${ }^{10}$ Difference between June 21 and December 21.
} 
how load profiles could be used to address the issues related to demand-side management, PV integration, and load forecasting. In the final section, we proposed a methodology to estimate the cooling load in Qatar and showed that more than half of the electricity was consumed for cooling during summer months.

\section{Acknowledgements}

The authors would like to thank the anonymous reviewers for their valuable comments and suggestions to improve the quality of the paper. Authors gratefully acknowledge the support of Luis Pomares, Daniel Perez Astudillo, Omar Alrawi, and Saiyed Wahadj for their assistance in writing the paper. 


\section{References}

[1] I. S. Bayram, M. Koc, Demand side management for peak reduction and pv integration in qatar, in: 14th IEEE International Conference on Networking, Sensing and Control, 2017, pp. 1-5.

[2] I. S. Bayram, O. Elrawi, H. Al-Naimi, M. Koc, Direct load control of air conditioners in qatar: An empirical study, in: International Conference on Renewable Energy Research and Applications, 2017, pp. 1-5.

[3] F. Saffouri, I. S. Bayram, M. Koc, Quantifying the cost of cooling in qatar, in: IEEE GCC Conference and Exhibition, 2017, pp. 1-5.

[4] L. Martin-Pomares, D. Martinez, J. Polo, D. Perez-Astudillo, D. Bachour, A. Sanfilippo, Analysis of the long-term solar potential for electricity generation in qatar, Renewable and Sustainable Energy Reviews 73 (2017) 1231 - 1246.

[5] B. Guo, W. Javed, B. W. Figgis, T. Mirza, Effect of dust and weather conditions on photovoltaic performance in doha, qatar, in: 2015 First Workshop on Smart Grid and Renewable Energy (SGRE), 2015, pp. $1-6$.

[6] N. Kumar, P. Besuner, S. Lefton, D. Agan, D. Hilleman, Power plant cycling costs, Tech. rep., National Renewable Energy Laboratory (NREL), Golden, CO. (2012).

[7] Gulf cooperation council (gcc) energy price reforms in the gcc. what can be learned from international experiences?, Tech. rep., International Monetary Fund (2015).

[8] G. Aneiros, J. Vilar, P. Raña, Short-term forecast of daily curves of electricity demand and price, International Journal of Electrical Power \& Energy Systems 80 (2016) 96-108.

[9] E. A. Feinberg, D. Genethliou, Load forecasting, Applied mathematics for restructured electric power systems (2005) 269-285.

[10] R. Weron, Modeling and forecasting electricity loads and prices: A statistical approach, Vol. 403, John Wiley \& Sons, 2007. 
[11] H. Hahn, S. Meyer-Nieberg, S. Pickl, Electric load forecasting methods: Tools for decision making, European journal of operational research 199 (3) (2009) 902-907.

[12] A. Srivastava, A. S. Pandey, D. Singh, Short-term load forecasting methods: A review, in: Emerging Trends in Electrical Electronics \& Sustainable Energy Systems (ICETEESES), International Conference on, IEEE, 2016, pp. 130-138.

[13] F. Apadula, A. Bassini, A. Elli, S. Scapin, Relationships between meteorological variables and monthly electricity demand, Applied Energy 98 (2012) 346-356.

[14] T. Hong, W.-K. Chang, H.-W. Lin, A fresh look at weather impact on peak electricity demand and energy use of buildings using 30-year actual weather data, Applied Energy 111 (2013) 333-350.

[15] A. Vaghefi, M. Jafari, E. Bisse, Y. Lu, J. Brouwer, Modeling and forecasting of cooling and electricity load demand, Applied Energy 136 (2014) 186-196.

[16] H. Son, C. Kim, Short-term forecasting of electricity demand for the residential sector using weather and social variables, Resources, Conservation and Recycling.

[17] A. Gastli, Y. Charabi, R. A. Alammari, A. M. Al-Ali, Correlation between climate data and maximum electricity demand in qatar, in: GCC Conference and Exhibition (GCC), 2013 7th IEEE, IEEE, 2013, pp. 565-570.

[18] İ. Ş. Bayram, H. Mohsenian-Rad, An overview of smart grids in the gec region, in: Smart City 360, Springer, 2016, pp. 301-313.

[19] D. Bachour, D. Perez-Astudillo, Ground measurements of global horizontal irradiation in doha, qatar, Renewable energy 71 (2014) 32-36.

[20] A. Kimber, L. Mitchell, S. Nogradi, H. Wenger, The effect of soiling on large grid-connected photovoltaic systems in california and the southwest region of the united states, in: Photovoltaic Energy Conversion, Conference Record of the 2006 IEEE 4th World Conference on, Vol. 2, IEEE, 2006, pp. 2391-2395. 
[21] W. Javed, Y. Wubulikasimu, B. Figgis, B. Guo, Characterization of dust accumulated on photovoltaic panels in doha, qatar, Solar Energy 142 (Supplement C) (2017) 123 - 135. doi:https://doi.org/10.1016/j.solener.2016.11.053.

URL http://www.sciencedirect.com/science/article/pii/ S0038092X1630593X

[22] Y. Chen, T. Hong, M. A. Piette, Automatic generation and simulation of urban building energy models based on city datasets for city-scale building retrofit analysis, Applied Energy 205 (Supplement C) (2017) 323 - 335. doi:https://doi.org/10.1016/j.apenergy.2017.07.128.

[23] C. E. Kontokosta, C. Tull, A data-driven predictive model of city-scale energy use in buildings, Applied Energy 197 (Supplement C) (2017) 303 - 317. doi:https://doi.org/10.1016/j.apenergy.2017.04.005.

[24] G. Kazas, E. Fabrizio, M. Perino, Energy demand profile generation with detailed time resolution at an urban district scale: A reference building approach and case study, Applied Energy 193 (2017) 243-262.

[25] J. V. Paatero, P. D. Lund, A model for generating household electricity load profiles, International journal of energy research 30 (5) (2006) 273290.

[26] A. Grandjean, J. Adnot, G. Binet, A review and an analysis of the residential electric load curve models, Renewable and Sustainable Energy Reviews 16 (9) (2012) 6539-6565.

[27] L. G. Swan, V. I. Ugursal, Modeling of end-use energy consumption in the residential sector: A review of modeling techniques, Renewable and sustainable energy reviews 13 (8) (2009) 1819-1835.

[28] S. Werner, European space cooling demands, Energy 110 (2016) 148156.

[29] S. Pezzutto, M. De Felice, R. Fazeli, L. Kranzl, S. Zambotti, Status quo of the air-conditioning market in europe: Assessment of the building stock, Energies 10 (9) (2017) 1253.

[30] Qatar general electricity and water cooperation.

URL www.km.com.qa 
[31] Kahramaa, Statistics report 2015, Tech. rep., Qatar General Electricity and Water Corporation, Doha, Qatar (2017).

[32] Qatar monthly statistics bulletin.

URL http://www.mdps.gov.qa/en/media/Pages/QMS .aspx

[33] Gulf cooperation council interconnection authority.

URL http://www.gccia.com.sa/

[34] GCCIA, Annual report 2016, Tech. rep., Gulf Cooperation Council Interconnection Authority, Dammam, KSA (2016).

[35] Daily electricity and water consumption figures.

URL https://twitter.com/kahramaa/status/ $863982387323076608 /$ photo/1

[36] Kahramaa twitter account.

URL https://twitter.com/kahramaa

[37] I. S. Bayram, T. S. Ustun, A survey on behind the meter energy management systems in smart grid, Renewable and Sustainable Energy Reviews 72 (Supplement C) (2017) 1208 - 1232. doi:https://doi.org/10.1016/j.rser.2016.10.034.

URL http://www.sciencedirect.com/science/article/pii/ S1364032116306852

[38] A. Faruqui, N. Lessem, S. Sergici, Dynamic pricing works in a hot, humid climate, Tech. rep., Fortnightly Magazine (May 2017).

[39] A. Faruqui, Direct load control of residential air conditioners in texas, Public Utility Commission of Texas, Austin.

[40] European network of transmission system operators for electricity.

URL https://www.entsoe.eu/data/statistics/Pages/default. aspx

[41] J. Lazar, et al., Teaching the" duck" to Fly, Regulatory Assistance Project, 2016.

[42] People in germany are now being paid to consume electricity. URL http://www.independent.co.uk/environment/ 
renewable-energy-germany-negative-prices-electricity-wind-solar-a7024716. html

[43] NREL system advisor model.

URL https://sam.nrel.gov/

[44] H. Radhi, S. Sharples, Quantifying the domestic electricity consumption for air-conditioning due to urban heat islands in hot arid regions, Applied energy 112 (2013) 371-380.

[45] M. Santamouris, Cooling the buildings-past, present and future, Energy and Buildings 128 (2016) 617-638.

[46] P. Denholm, S. Ong, C. Booten, Using utility load data to estimate demand for space cooling and potential for shiftable loads, Tech. rep., National Renewable Energy Laboratory (NREL), Golden, CO. (2012). 